\title{
Investigating the source, transport, and isotope composition of water vapor in the planetary boundary layer
}

\author{
Timothy J. Griffis ${ }^{1}$, Jeffrey D. Wood ${ }^{1}$, John M. Baker ${ }^{1,2}$, Xuhui Lee ${ }^{3,4}$, Ke Xiao $^{1}$, Zichong Chen ${ }^{1}$, Lisa R. Welp ${ }^{5}$, \\ Natalie M. Schultz ${ }^{3}$, Galen Gorski ${ }^{1}$, Ming Chen ${ }^{1}$, and John Nieber ${ }^{6}$ \\ ${ }^{1}$ Department of Soil, Water, and Climate, University of Minnesota, Saint Paul, MN, USA \\ ${ }^{2}$ United States Department of Agriculture - Agricultural Research Service, Saint Paul, MN, USA \\ ${ }^{3}$ School of Forestry and Environmental Studies, Yale University, New Haven, CT, USA \\ ${ }^{4}$ Yale-NUIST Center on Atmospheric Environment, Nanjing University of Information, \\ Science and Technology, Nanjing, China \\ ${ }^{5}$ Earth, Atmospheric, and Planetary Sciences, Purdue University, West Lafayette, IN, USA \\ ${ }^{6}$ Department of Bioproducts and Biosystems Engineering, University of Minnesota, Saint Paul, MN, USA
}

Correspondence to: Timothy J. Griffis (timgriffis@umn.edu)

Received: 13 November 2015 - Published in Atmos. Chem. Phys. Discuss.: 18 January 2016

Revised: 4 April 2016 - Accepted: 13 April 2016 - Published: 25 April 2016

\begin{abstract}
Increasing atmospheric humidity and convective precipitation over land provide evidence of intensification of the hydrologic cycle - an expected response to surface warming. The extent to which terrestrial ecosystems modulate these hydrologic factors is important to understand feedbacks in the climate system. We measured the oxygen and hydrogen isotope composition of water vapor at a very tall tower $(185 \mathrm{~m})$ in the upper Midwest, United States, to diagnose the sources, transport, and fractionation of water vapor in the planetary boundary layer (PBL) over a 3-year period (2010 to 2012). These measurements represent the first set of annual water vapor isotope observations for this region. Several simple isotope models and cross-wavelet analyses were used to assess the importance of the Rayleigh distillation process, evaporation, and PBL entrainment processes on the isotope composition of water vapor. The vapor isotope composition at this tall tower site showed a large seasonal amplitude (mean monthly $\delta^{18} \mathrm{O}_{\mathrm{v}}$ ranged from -40.2 to $-15.9 \%$ and $\delta^{2} \mathrm{H}_{\mathrm{v}}$ ranged from -278.7 to $-113.0 \%$ ) and followed the familiar Rayleigh distillation relation with water vapor mixing ratio when considering the entire hourly data set. However, this relation was strongly modulated by evaporation and $\mathrm{PBL}$ entrainment processes at timescales ranging from hours to several days. The wavelet coherence spectra indicate that the oxygen isotope ratio and the deuterium excess $\left(d_{\mathrm{v}}\right)$ of water vapor are sensitive to synoptic and PBL
\end{abstract}

processes. According to the phase of the coherence analyses, we show that evaporation often leads changes in $d_{\mathrm{v}}$, confirming that it is a potential tracer of regional evaporation. Isotope mixing models indicate that on average about $31 \%$ of the growing season PBL water vapor is derived from regional evaporation. However, isoforcing calculations and mixing model analyses for high PBL water vapor mixing ratio events ( $>25 \mathrm{mmol} \mathrm{mol}^{-1}$ ) indicate that regional evaporation can account for 40 to $60 \%$ of the PBL water vapor. These estimates are in relatively good agreement with that derived from numerical weather model simulations. This relatively large fraction of evaporation-derived water vapor implies that evaporation has an important impact on the precipitation recycling ratio within the region. Based on multiple constraints, we estimate that the summer season recycling fraction is about $30 \%$, indicating a potentially important link with convective precipitation.

\section{Introduction}

There is unequivocal evidence that the global water cycle has been intensified by anthropogenic warming (Chung et al., 2014; Trenberth et al., 2007a; Santer et al., 2007). Global analyses demonstrate that water vapor is increasing over the oceans (Santer et al., 2007), at continental locations (Dai, 
2006), and in the upper troposphere (Chung et al., 2014). Quantifying and elucidating the processes underlying the variability in atmospheric water vapor remains one of the grand challenges in water cycle science (Trenberth and Asrar, 2014).

Higher water vapor concentrations are expected to have important impacts on climate (Trenberth et al., 2007a). Water vapor is the dominant greenhouse gas, accounting for about $50 \%$ of the long-wave radiative forcing (Schmidt et al., 2010), and also plays a key role in atmospheric aerosol formation (Nguyen et al., 2015) and therefore shortwave radiative forcing. Furthermore, water vapor is an active scalar influencing static stability and convection. There is growing evidence that the frequency and magnitude of convective precipitation events are increasing as a result of surface warming and higher humidity (Trenberth et al., 2007a; Trenberth, 2011; Min et al., 2011).

Interpreting the variations in water vapor over continental locations is challenging because there are many different sources, transport processes, and phase changes that influence water vapor history on a variety of temporal and spatial scales. In recent years there have been important technical advances that have enhanced our ability to quantify the oxygen $\left(\delta^{18} \mathrm{O}\right)$ and deuterium $\left(\delta^{2} \mathrm{H}\right)$ isotope composition of water vapor and evaporation using optical isotope techniques (Lee et al., 2005; Wen et al., 2008; Welp et al., 2008; Wang et al., 2010; Johnson et al., 2011; Noone et al., 2013; Griffis, 2013). These technical advances are now providing high density data sets that can be used to diagnose how hydrometeorological factors (i.e., air mass back trajectories, precipitation, evaporation, and snow sublimation) (Lee et al., 2006; Noone et al., 2013; Farlin et al., 2013; Soderberg et al., 2013; Aemisegger et al., 2014; Delattre et al., 2015) and biophysical factors (i.e., transpiration, soil evaporation) (Welp et al., 2008; Hu et al., 2014; Simonin et al., 2014) influence landatmosphere water vapor exchange and the sources of water contributing to atmospheric water vapor.

The isotope composition of water vapor in the planetary boundary layer (PBL) can vary strongly on seasonal and diurnal timescales depending on geographical location (Welp et al., 2012). Diurnal variations have been linked to PBL entrainment processes (Lai and Ehleringer, 2011; Lee et al., 2012; Welp et al., 2012; Noone et al., 2013) and evaporation (Lee et al., 2007; Griffis et al., 2010b; Lai and Ehleringer, 2011; Welp et al., 2012; Huang and Wen, 2014). There is growing consensus that water vapor deuterium excess $\left(d_{\mathrm{v}}=\right.$ $\delta^{2} \mathrm{H}-8 \delta^{18} \mathrm{O}$ ) is not a conserved quantity of marine evaporation conditions as once thought, but that it is highly sensitive to changes in evaporation and PBL processes (Welp et al., 2012; Zhao et al., 2014; Huang and Wen, 2014). The high sensitivity of isotopes in water vapor, $\delta^{2} \mathrm{H}_{\mathrm{v}}, \delta^{18} \mathrm{O}_{\mathrm{v}}$, and $d_{\mathrm{v}}$ to evaporation may, therefore, offer new insights regarding the controls and water sources influencing continental atmospheric water vapor and precipitation.
Here, we examine the temporal scales and extent to which Rayleigh distillation (i.e., the removal of water vapor from the air mass via condensation and precipitation), evaporation (including transpiration), and PBL growth processes influence the isotope compositions $\left(\delta^{2} \mathrm{H}_{\mathrm{v}}, \delta^{18} \mathrm{O}_{\mathrm{v}}\right.$, and $\left.d_{\mathrm{v}}\right)$ of midcontinental atmospheric water vapor as observed in the upper Midwest, United States. We then use these tracers to help constrain the precipitation recycling fraction at the tall tower site. Figure 1 provides an overview of our investigation and illustrates the spatial domain and methodological approach. We bring together a unique multi-year (2010-2012) record of tall tower water vapor mixing ratio (major and minor isotopes), precipitation isotope ratios (2006-2011), surface vapor flux observations, cross-wavelet analyses, and numerical modeling to evaluate the following hypotheses.

1. The isotope composition of the PBL within this region is largely determined by air mass Rayleigh distillation, but is strongly modulated by evaporation at timescales ranging from hours to days.

2. The deuterium isotope signal in PBL water vapor is most strongly influenced by regional evaporation.

3. The growing season water vapor concentration in the PBL is dominated by regional evaporation from croplands.

4. Growing season precipitation events are comprised of a significant contribution of regional evaporation and therefore exhibit a relatively high degree of moisture recycling.

\section{Methodology}

\subsection{Study site}

The measurements reported in this study were made at the University of Minnesota tall tower trace gas observatory (TGO KCMP, Minnesota Public Radio tower, $44^{\circ} 41^{\prime} 19^{\prime \prime} \mathrm{N}$, $93^{\circ} 4^{\prime} 22^{\prime \prime} \mathrm{W}$; $290 \mathrm{~m}$ a.s.1.). The tall tower $(244 \mathrm{~m})$ is located about $25 \mathrm{~km}$ south of Saint Paul, Minnesota (Fig. 1). It was instrumented in spring 2007 with air sample inlets at 32, 56,100 , and $185 \mathrm{~m}$. Three-dimensional sonic anemometerthermometers (CSAT3, Campbell Scientific Inc., Logan, Utah, USA) are mounted at 100 and $185 \mathrm{~m}$, with signals transmitted to data loggers and computers via fiber optic cables and modems (Griffis et al., 2010a). Scalars including carbon dioxide, water vapor, nitrous oxide, methane, isoprene, and other trace gases have been measured at the site since 2007 (Griffis et al., 2010a, 2013; Hu et al., 2015a, b). Land use in the vicinity of the tall tower (extending from 10 to $600 \mathrm{~km}$ radius) consists of about $40 \%$ agriculture (mainly corn and soybean) that is typical of the US Corn Belt (Griffis et al., 2013; Zhang et al., 2014). The concentration footprint 


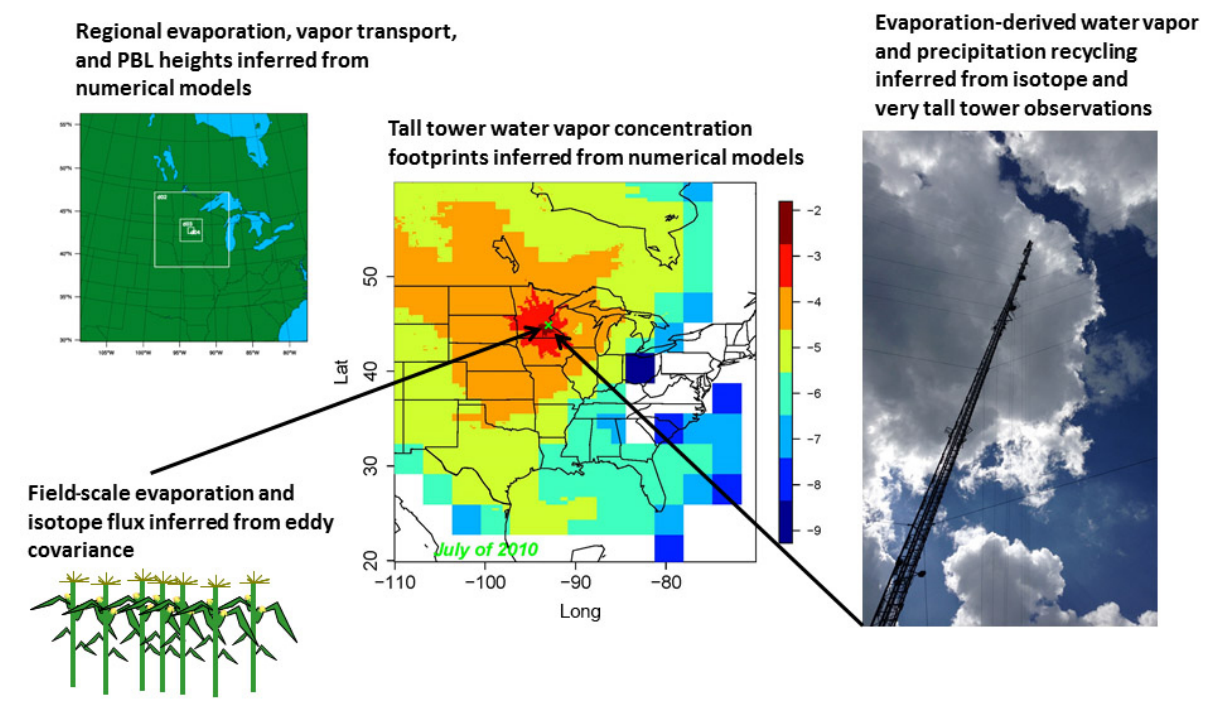

Figure 1. Overview of research approach, illustrating the tall tower location and study domain. A synthesis of tall tower water vapor and isotope observations, field-scale flux measurements, and numerical simulations were used to examine how evaporation and planetary boundary layer processes influence water vapor and water recycling within the region.

of the tall tower ( $185 \mathrm{~m}$ sample inlet) when coupled to inverse model analyses has shown to be representative of the upper Midwest, United States, for a number of active and passive scalars (Zhang et al., 2014; Hu et al., 2015b). Here, we define the regional domain of the observations on the order of $80 \mathrm{~km} \times 80 \mathrm{~km}$, which is consistent with the numerical modeling described below.

\subsection{Isotope measurements}

The oxygen and hydrogen isotopes in water vapor were measured in situ using a tunable diode laser (model TGA200, Campbell Scientific Inc., Logan, Utah, USA) (Lee et al., 2005; Griffis et al., 2010b). These measurements were initiated in April 2010. A large diaphragm pump (1023-101QSG608X, GAST Manufacturing Inc., Benton Harbor, Michigan, USA) pulled air continuously at $3 \mathrm{~L} \mathrm{~min}^{-1}$ down sample tubing (Synflex Type 1300, Aurora, OH, USA) at the TGO to the analyzer that was maintained inside the climatecontrolled radio broadcast building. The sample inlets used in this investigation were located at approximately 185 and $3 \mathrm{~m}$ above the ground surface. The tubing was heated from the base of the tower to the laser sample inlet, a distance of about $30 \mathrm{~m}$, to prevent condensation. The sampling scheme consisted of a $10 \mathrm{~min}(600 \mathrm{~s})$ cycle: (1) zero calibration with ultra dry air (110s), (2) calibration with three span values $(15 \mathrm{~s} / \mathrm{each}$ ) for the $3 \mathrm{~m}$ inlet, (3) sampling of the $3 \mathrm{~m}$ inlet (145 s), (4) zero calibration with ultra dry air (110 s), (5) calibration with three span values $(15 \mathrm{~s} / \mathrm{each})$ for the $185 \mathrm{~m}$ inlet, and (6) sampling of the $185 \mathrm{~m}$ inlet (145 s). The three calibration span values dynamically tracked and bracketed the total ambient water vapor mixing ratios through time. The isotope composition of the span values was determined by the calibration dripper source water, which was maintained at approximately -60.0 and $-8.5 \%$ or $\delta^{2} \mathrm{H}, \delta^{18} \mathrm{O}$, respectively (Griffis et al., 2010b). An omit time of $5 \mathrm{~s}$ was used on the calibration spans and air samples, and a $90 \mathrm{~s}$ omit time was used for the dry air calibration. Given the low pressure of the subsample inlets $(40 \mathrm{kPa})$ and tunable diode laser sample cell $(0.8 \mathrm{kPa})$, the equilibration time of the system was relatively fast, on the order of $5 \mathrm{~s}$ for the span calibrations and $30 \mathrm{~s}$ for the zero calibration. Further details regarding the measurement system and calibration techniques and uncertainties are described in Griffis et al. (2010b). All raw data were recorded at $10 \mathrm{~Hz}$ using a data logger and then blockaveraged into $1 \mathrm{~h}$ intervals. The hourly water vapor signals were filtered using an outlier detection algorithm based on the double-differenced time series that identifies outliers according to the median absolute deviation about the median values (Sachs, 1996; Papale et al., 2006).

Precipitation samples have been collected from RROC, and at the University of Minnesota, Saint Paul campus, from January 2006 to present using a typical all-weather rain gauge with mineral oil added to eliminate evaporative fractionation effects. Samples were typically collected within 0 3 days of precipitation events and transferred to screw-top glass vials, sealed with Parafilm, and refrigerated until analysis. The timing and amount of rainfall was recorded using a tipping bucket rain gauge (6028-B, All Weather Inc., CA, USA) and snowfall was measured using a snow board provided by the Minnesota State Climate Office (http://climate. umn.edu/doc/journal/snowboard.doc). Leaf, stem, and soil samples were collected from within a $5 \mathrm{~km}$ radius of the tall tower during numerous campaigns and as part of the International Atomic Energy Agency's Moisture Isotopes in the Bio- 
sphere and Atmosphere (IAEA-MIBA) program. Vegetation sampling sites chosen for this analysis were representative of the local land cover characteristics, including corn (Zea mays L.), soybean (Glycine max), and big bluestem (Andropogon gerardii Vitman). The MIBA sampling protocol was followed. Sunlit leaves, non-green stems, and soil approximately $10 \mathrm{~cm}$ below the surface were collected near midday (12:00 local standard time, LST). Cryogenic vacuum distillation (Welp et al., 2008; Schultz et al., 2011) was used to extract water from the plant and soil samples. Surface (i.e., lake and river) water and ground water samples were also collected from within a $25 \mathrm{~km}$ radius of the tall tower.

All liquid water samples were analyzed for their isotope composition using an off-axis cavity ring-down infrared laser spectroscopy system (Liquid Water Isotope Analyzer, DLT-100, Los Gatos Research, Inc., Mountain View, California) coupled to an autosampler (HT-300A, HTA s.r.l., Brescia, Italy) for simultaneous measurements of ${ }^{2} \mathrm{H} /{ }^{1} \mathrm{H}$ and ${ }^{18} \mathrm{O} /{ }^{16} \mathrm{O}$. This instrument has a precision of $\pm 1.0 \%$ for ${ }^{2} \mathrm{H} /{ }^{1} \mathrm{H}$ and $\pm 0.25 \%$ o for ${ }^{18} \mathrm{O} /{ }^{16} \mathrm{O}$. Precalibrated laboratory standards used to calibrate the unknown samples to the VSMOW scale were selected based on the expected isotope composition of the unknown samples, and were injected after every two unknown samples to correct for instrumental drift. Linear calibration equations were calculated using each set of standards throughout the autorun and used to correct unknown samples. Contamination of plant water samples by ethanol/methanol was corrected following the procedures described by Schultz et al. (2011).

\subsection{Wavelet analyses}

Signals were analyzed using techniques based on the continuous wavelet transform (CWT). Wavelet-based techniques are particularly suited to analyzing non-stationary geophysical time series because signals are simultaneously decomposed into time-frequency space. See Daubechies (1990) and Torrence and Compo (1998) for an overview of the theoretical background and practical application. Here, we use crosswavelet analyses to help elucidate how different atmospheric processes influence the isotope composition of PBL water vapor and to better understand the patterns and timescales of those relations.

Briefly, all CWTs were calculated on the fluctuating component of the signal using the complex Morlet wavelet basis with the nondimensional frequency $\left(\omega_{0}\right)$ set to 6 (Torrence and Compo, 1998) to obtain a good balance between time and frequency localization (Grinsted et al., 2004). Another desirable feature of the Morlet wavelet basis with $\omega_{0}=6$ is that the scales map closely to an analogous Fourier pe$\operatorname{riod}(\lambda)$ according to $\lambda=1.03 \mathrm{~s}$ (Torrence and Compo, 1998), where $s$ is the scale, and the dimension of both $\lambda$ and $s$ is time. Scales were set to have a minimum of $2 \mathrm{~h}$ (i.e., twice the hourly averaging interval), and to have 12 suboctaves per octave. Calculating the CWT of the signal yields a set of wavelet coefficients, $W_{n}(s)$, spanning all times $(n)$ and scales. Here, we concern ourselves with disentangling the effects of different processes on PBL water vapor, and thus employ the multivariate technique known as wavelet coherence analysis to probe correlation and phase relationships between variables.

The cross-wavelet spectrum, $S_{n}^{X Y}(s)$, of two time series, $X_{n}$ and $Y_{n}$, is obtained from the wavelet coefficients calculated for the respective variables according to

$S_{n}^{X Y}(s)=W_{n}^{X}(s) W_{n}^{Y}(s)^{*}$,

where * represents complex conjugation (Grinsted et al., 2004). The cross-wavelet spectrum identifies regions of high common power, but does not provide information regarding the coherency between the signals.

To examine the coherency of the cross-wavelet transform in time-frequency space, we made use of the wavelet coherence spectrum, $R_{n}^{2}(s)$, that is defined according to

$R_{n}^{2}(s)=\frac{\left|\Lambda\left(s^{-1} S_{n}^{X Y}(s)\right)\right|^{2}}{\Lambda\left(s^{-1}\left|S_{n}^{X}(s)\right|^{2}\right) \Lambda\left(s^{-1}\left|S_{n}^{Y}(s)\right|^{2}\right)}$,

where $\Lambda$ represents a smoothing operator and its definition can be found in Grinsted et al. (2004) (see their Eqs. 9 and 10). A useful interpretation of the coherence spectrum is that values of $R_{n}^{2}(s)$ represent local correlation coefficients in time-frequency space (Grinsted et al., 2004). Statistical significance testing was performed using the Monte Carlo approach described in Grinsted et al. (2004). All wavelet analyses were implemented using the package of MATLAB functions developed by Grinsted et al. (2004), which is available at http://www.glaciology.net/wavelet-coherence.

\subsection{Numerical modeling}

We used the National Center for Atmospheric Research (NCAR) Weather Research and Forecasting (WRF) model version 3.5 to simulate the regional surface latent heat flux, PBL height, and to examine other controls on the regional water vapor (Chen et al., 1996). The simulations made use of four nested domains (with a recommended 3:1 ratio for inner domains), with the innermost domain containing the location of the tall tower. The inner domain 4 occupied the smallest area $(80 \times 80 \mathrm{~km})$ and employed a $1 \mathrm{~km}$ grid resolution (see Fig. S1 in the Supplement). In these simulations a two-way feedback among the nested domains was turned on. The NOAH land surface scheme option was selected for all WRF simulations for three reasons: (1) it has been used extensively in the literature; (2) we have been using WRF-NOAH to forecast evaporation for our region and have tested it extensively against eddy covariance flux observations; and (3) the WRF-NOAH system is computationally efficient compared to other options such as WRF-CLM (Community Land Model surface scheme option). The WRF-NOAH simulations used land cover information from the United States Geological Survey (USGS) 
land use product, which includes 24 land use categories. The WRF settings (namelist file) used to run these simulations are provided in the Supplement. Boundary and initial conditions were provided by the NCEP FNL Operational Global Analysis data product with a $1^{\circ} \times 1^{\circ}$ resolution at $6 \mathrm{~h}$ intervals (National Centers for Environmental Prediction/National Weather Service/NOAA/U.S. Department of Commerce, 2000; http://rda.ucar.edu/datasets/ds083.2/). Further, the Stochastic Time-Inverted Lagrangian Transport (STILT) model (Lin et al., 2003; Gerbig et al., 2003) was used to examine the water vapor concentration source footprint associated with an extreme dew point event at the tall tower. The meteorological fields required to drive STILT were obtained from the WRF simulations. Since water vapor is an active scalar, the STILT source footprints computed here likely represent the maximum spatial extent of influence with respect to the tall tower observations. All of these model simulations were run on an HP ProLiant BL280c G6 Linux Cluster at the University of Minnesota Supercomputing Institute (https://www.msi.umn.edu/).

\subsection{Basic isotope theory}

The isotope composition of precipitation and water vapor is reported as

$\delta=\frac{R_{\mathrm{s}}-R_{\mathrm{std}}}{R_{\text {std }}}$,

where $\delta$ is the isotope ratio. All values are reported in parts per thousand (\%o) by multiplying $\delta$ by $10^{3} . R_{\mathrm{S}}$ is the sample molar ratio of the heavy (minor) to light (major) isotope (i.e., ${ }^{18} \mathrm{O} /{ }^{16} \mathrm{O}$ or ${ }^{2} \mathrm{H} /{ }^{1} \mathrm{H}$ ) and $R_{\text {std }}$ is the standard molar ratio defined according to the VSMOW scale.

We make use of precipitation events to examine the isotope composition of water vapor in relation to the falling precipitation. In theory, if atmospheric humidity is at saturation below the cloud base, then thermodynamic equilibrium is expected for isotope exchange between the liquid water and atmospheric vapor (Stewart, 1975):

$R_{\mathrm{v}}=\frac{R_{\mathrm{L}}}{\alpha}$,

where $R_{\mathrm{v}}$ is the absolute isotope ratio of water vapor $\left({ }^{18} \mathrm{O} /{ }^{16} \mathrm{O}\right.$ or $\left.{ }^{2} \mathrm{H} /{ }^{1} \mathrm{H}\right), \alpha$ is the equilibrium fractionation factor (isotope-specific), and $R_{\mathrm{L}}$ is the isotope ratio of the liquid water (rain precipitation) (Majoube, 1971; Jouzel, 2003; Lee et al., 2005). Under these conditions, the equilibrium relation can provide a useful diagnostic regarding the validity of the tall tower water vapor isotope ratios or the influence of evaporation of raindrops and humidification of the PBL.

The global meteoric water line (GMWL),

$\delta^{2} \mathrm{H}=8 \delta^{18} \mathrm{O}+10$,

represents the linear relation between $\delta^{2} \mathrm{H}$ and $\delta^{18} \mathrm{O}$ for global precipitation and is a useful benchmark for examining the origin, modification, and history of other water sources (Craig, 1961; Gat, 1996). The GMWL parameters are derived from empirical observations and are related to Rayleigh distillation processes (Gat and Airey, 2006). The slope of $\approx 8$ results from the equilibrium condensation conditions and the ratio of the equilibrium fractionation factors (Jouzel, 2003). The intercept of $\approx 10$ is determined by the average equilibrium and kinetic fractionation factors for oceanatmosphere exchange with a global evaporation-weighted mean relative humidity of $\approx 85 \%$ (Clark and Fritz, 1997). Sources of water undergoing evaporation result in isotope kinetic effects that cause $\delta^{2} \mathrm{H}-\delta^{18} \mathrm{O}$ slopes less than 8 (Dansgaard, 1964; Gat et al., 1994; Gat and Airey, 2006).

Three simple models were used to aid the interpretation of the tall tower $\delta^{18} \mathrm{O}_{\mathrm{v}}$ data. These models were selected because their physics are well understood and they represent three idealized processes that influence the behavior of water vapor in the PBL (Worden et al., 2007; Lee et al., 2006). First, a classic Rayleigh model (RM1) assuming a closed system with no rainout was assessed (Lee et al., 2006):

$\delta_{\mathrm{RM} 1}=1000(\alpha-1)\left(\log \left(\chi_{\mathrm{w}}\right)-\log \left(\chi_{\mathrm{o}}\right)\right)+\delta_{\mathrm{o}}$,

where $\alpha$ is the equilibrium fractionation factor evaluated at a condensation temperature of $-3^{\circ} \mathrm{C}$ (this represents the mean adiabatically adjusted temperature at the lifted condensation level). Here, the initial air mass is assumed to have an oceanic source region with a water vapor mixing ratio $\left(\chi_{0}\right)$ of $35 \mathrm{mmol} \mathrm{mol}^{-1}$ and an oxygen isotope ratio $\left(\delta_{0}\right)$ of $-10 \%$ (Worden et al., 2007). While these initial values are somewhat arbitrary, it is the variation in the response function relative to the observations that is of primary interest. Second, a Rayleigh model (RM2) with a rainout fraction $(f)$ of $30 \%$ was evaluated:

$$
\begin{aligned}
\delta_{\mathrm{RM} 2}= & 1000(\alpha(1-f / \alpha) /(1-f)-1)\left(\log \left(\chi_{\mathrm{w}}\right)\right. \\
& \left.-\log \left(\chi_{\mathrm{o}}\right)\right)+\delta_{\mathrm{o}},
\end{aligned}
$$

where precipitation/condensate is removed, causing the isotope composition of the water vapor to become more depleted (Worden et al., 2007; Lee et al., 2006). Finally, a simple two-source evaporation mixing model (EM1, a Keeling plot, Keeling, 1958) was examined:

$\delta_{\mathrm{EM} 1}=\frac{\chi_{\mathrm{b}}}{\chi_{\mathrm{w}}}\left(\delta_{\mathrm{b}}-\delta_{\mathrm{E}}\right)+\delta_{\mathrm{E}}$,

that considers surface evaporation into an air mass. $\chi_{w}$ and $\chi_{\mathrm{b}}$ represent the air mass and background water vapor mixing ratios, respectively. Here, the oxygen isotope ratio of evaporation $\left(\delta_{\mathrm{E}}\right)$ is taken as $-6.2 \%$, which is based on the growing season (May to September) tall tower oxygen isotope fluxgradient measurements (Table 1).

Finally, we optimized the RM1 and EM1 models to determine the equilibrium fractionation factor and the isotope composition of surface evaporation, respectively, that best fit the tall tower data. These optimized models are referred 
Table 1. Tall tower water vapor isotope climatology. All water vapor related data were measured at the tall tower from April 2010 to December 2012. Note that isoforcing and flux ratio values for deuterium are not reported for the non-growing season due to very low signal-to-noise ratios. All values in parentheses represent 1 standard deviation of the hourly values for the specified period.

\begin{tabular}{|c|c|c|c|c|c|c|c|c|}
\hline Month & $\left(\mathrm{mmol} \mathrm{mol}^{-1}\right)$ & $\begin{array}{r}\delta^{18} \mathrm{O}_{\mathrm{v}}^{\mathrm{b}} \\
(\% o)\end{array}$ & $\begin{array}{r}\delta^{2} \mathrm{H}_{\mathrm{V}}^{\mathrm{b}} \\
(\% \circ)\end{array}$ & $\begin{array}{r}d_{\mathrm{v}}^{\mathrm{b}} \\
(\% o)\end{array}$ & $\begin{array}{l}\text { Isof- }{ }^{18} \mathrm{O}^{\mathrm{c}} \\
\left(\mathrm{m} \mathrm{s}^{-1} \% \mathrm{o}\right)\end{array}$ & $\begin{array}{r}\text { Isof- }{ }^{2} \mathrm{H}^{\mathrm{c}} \\
\left(\mathrm{m} \mathrm{s}^{-1} \% \mathrm{o}\right)\end{array}$ & $\begin{array}{r}\delta_{\mathrm{E}}^{18} \mathrm{O}^{\mathrm{d}} \\
(\% o)\end{array}$ & $\begin{array}{r}\delta_{\mathrm{E}}^{2} \mathrm{H}^{\mathrm{d}} \\
(\% o)\end{array}$ \\
\hline Jan & $2.3(1.4)$ & $-40.2(5.3)$ & $-278.7(46.8)$ & $35.6(41.3)$ & $0.0019(0.014)$ & - & $-22.5(32.6)$ & - \\
\hline Feb & $3.0(2.1)$ & $-34.7(6.8)$ & $-232.4(50.2)$ & $31.2(49.8)$ & $0.0024(0.023)$ & - & $-31.1(24.7)$ & - \\
\hline Mar & $5.8(4.6)$ & $-27.2(7.1)$ & $-185.4(46.3)$ & $24.1(35.6)$ & $0.0002(0.026)$ & - & $-25.2(38.7)$ & - \\
\hline Apr & $6.3(3.1)$ & $-25.0(5.3)$ & $-171.0(38.5)$ & $23.1(28.0)$ & $0.0090(0.030)$ & - & $-10.0(17.2)$ & - \\
\hline May & $9.8(5.5)$ & $-21.5(5.5)$ & $-139.2(42.5)$ & $20.8(39.9)$ & $0.0073(0.037)$ & $0.0071(0.136)$ & $-10.4(23.0)$ & $-69.4(57.7)$ \\
\hline Jun & $13.8(6.5)$ & $-18.3(4.5)$ & $-123.6(32.7)$ & $20.9(17.7)$ & $0.0086(0.036)$ & $0.0054(0.113)$ & $-4.6(12.3)$ & $-79.0(39.8)$ \\
\hline Jul & $20.5(5.0)$ & $-15.9(4.4)$ & $-113.0(31.5)$ & $17.2(16.0)$ & $0.0049(0.031)$ & $0.0157(0.132)$ & $-5.0(6.7)$ & $-61.0(38.3)$ \\
\hline Aug & $17.3(6.8)$ & $-18.8(4.9)$ & $-132.5(32.0)$ & $20.8(21.4)$ & $0.0062(0.059)$ & $0.0001(0.097)$ & $-5.0(9.0)$ & $-101.6(33.7)$ \\
\hline Sept & $11.3(4.6)$ & $-23.7(5.7)$ & $-151.2(40.9)$ & $32.0(36.7)$ & $0.0071(0.030)$ & - & $-6.2(20.1)$ & - \\
\hline Oct & $7.6(3.7)$ & $-25.1(5.7)$ & $-162.5(43.6)$ & $32.3(37.5)$ & $0.0020(0.025)$ & - & $-8.7(33.0)$ & - \\
\hline Nov & $5.6(2.3)$ & $-27.7(6.6)$ & $-179.5(45.1)$ & $35.1(45.9)$ & $0.0029(0.026)$ & - & $-19.1(39.8)$ & - \\
\hline Dec & $2.9(1.6)$ & $-35.9(9.2)$ & $-243.3(64.0)$ & $47.8(54.5)$ & $0.0027(0.027)$ & - & $-12.0(35.5)$ & - \\
\hline Mean & 8.9 & -26.2 & -176.0 & 28.4 & 0.0046 & 0.0071 & -13.3 & -77.8 \\
\hline
\end{tabular}

to as BestFitRM and BestFitEM, respectively. These models were fit to the observed tall tower data using a nonlinear fitting algorithm (fitnlm) implemented using Matlab (Matlab Version 2013b, The Mathworks Inc., Natick, Massachusetts, USA).

The isoforcing $\left(I_{F}\right)$ approach (Lee et al., 2009; Griffis et al., 2010a) was used to help interpret short-term (hourly) variations in the water vapor isotope observations:

$I_{F}=\frac{E}{C_{a}}\left(\delta_{\mathrm{E}}-\delta_{\mathrm{v}}\right)$,

where $C_{a}$ is the molar density of water vapor, $\delta_{\mathrm{E}}$ is the oxygen isotope composition of evaporation as determined from the tall tower flux-gradient measurements (Schultz, 2011), and $\delta_{\mathrm{v}}$ is the oxygen isotope composition of the water vapor in the PBL. The $I_{F}$ calculations are used to isolate the influence of surface evaporation on $\delta_{\mathrm{v}}$. Although the same approach can be applied using the deuterium isotopes, the atmospheric gradients are considerably smaller because the source strength is smaller, resulting in lower signal to noise ratios. As a result, we restricted our deuterium isoforcing calculations to May through August.

A simple two-member isotope mixing model was used to estimate the relative contribution of surface evaporation to the total water vapor concentration of the PBL:

$f_{\mathrm{v}}=\frac{\delta_{\mathrm{v}}-\delta_{\mathrm{b}}}{\delta_{\mathrm{E}}-\delta_{\mathrm{b}}}$,

where $f_{\mathrm{v}}$ is the fraction of vapor in the PBL derived from regional evaporation, $\delta_{\mathrm{v}}$ is the oxygen isotope composition of the water vapor measured at $185 \mathrm{~m}$, and $\delta_{\mathrm{b}}$ represents the oxygen isotope ratio of the "background" vapor, which can vary depending on synoptic meteorological conditions. Further, this approach does not explicitly account for the influence of advection. Direct observations of the oxygen isotope composition of background vapor for the region do not exist. However, we make use of a unique set of aircraft observations collected by He and Smith (1999) over New England, United States, in 1996. They obtained profiles of water vapor mixing ratio and $\delta^{18} \mathrm{O}_{\mathrm{v}}$ at altitudes ranging from $195 \mathrm{~m}$ to $2851 \mathrm{~m}$ during three campaigns (15 June, 17 July, and 12 October 1996). We have plotted their data in Fig. 2 and demonstrate that $\delta^{18} \mathrm{O}_{\mathrm{v}}$ follows a power law (Rayleigh) function with respect to water vapor mixing ratio $\left(y=a x^{b}\right.$, where $x$ is water vapor mixing ratio, $r^{2}=0.98, p<0.001$, $n=24)$ through the PBL. Here, we define the background signal assuming a power law relation for the tall tower site. In this approach, the theoretical background value was obtained by evaluating the power law relation with water vapor mixing ratio estimated at $700 \mathrm{hPa}$ (i.e., above the PBL at a standard atmosphere height of approximately $3000 \mathrm{~m}$ ) using reanalysis data provided by the National Centers for Environmental Prediction and the National Center for Atmospheric Research (NCEP/NCAR) Reanalysis-2 product. Over the 3year period the mean annual water vapor mixing ratio at $700 \mathrm{hPa}$ was $3.9 \mathrm{mmol} \mathrm{mol}^{-1}$, and was $5.9 \mathrm{mmol} \mathrm{mol}^{-1}$ during the growing season. With respect to the power law function, these mean values occur before the function reaches its vertical asymptote (i.e., where it becomes hypersensitive). However, as shown in Fig. 2, there are cases where the uncertainty in the background value will be large because of this sensitivity.

Constraints on the oxygen isotope composition of surface evaporation $\left(\delta_{\mathrm{E}}\right)$ were provided from multiple studies con- 


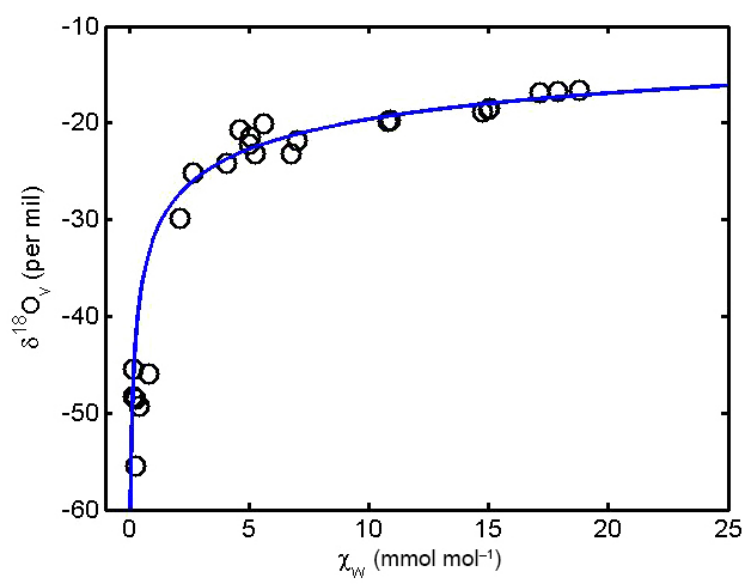

Figure 2. Aircraft observations of the oxygen isotope composition of water vapor $\left(\delta^{18} \mathrm{O}_{\mathrm{v}}\right)$ measured over a forested landscape in New England, United States (He and Smith, 1999; their Table 2). Data from three campaigns show that $\delta^{18} \mathrm{O}_{\mathrm{v}}$ follows a power law function $\left(y=-32.1 \chi_{\mathrm{W}}^{-0.213}\right)$ of water vapor mixing ratio $\left(r^{2}=0.98\right.$, $n=24, p<0.0001)$.

ducted near the tall tower. The oxygen isotope composition of evaporation was determined over a corn canopy using the eddy covariance approach (Griffis et al., 2010b, 2011). These studies showed that $\delta_{\mathrm{E}}$ ranged from -20 to $-5 \%$ with a mean flux-weighted value of $-7.7 \%$ for a 74 -day period in 2009 . The $\delta_{\mathrm{E}}$ of soybean crops has also been estimated within the study domain using the flux-gradient approach (Welp et al., 2008) with values ranging from about -30 to $+20 \%$ o with a mean flux-weighted value of $-4.8 \%$ over the period June to September 2006. Regional $\delta_{\mathrm{E}}$ has also been obtained from our tall tower flux-gradient observations. These values were similar to those reported for the above field-scale investigations with a mean flux-weighted value of $-6.2 \%$ for the 2010 to 2012 growing season (Table 1). Further, based on plant stem water extractions, and assuming steady-state conditions for the mid-afternoon to late afternoon period, the oxygen isotope composition of transpiration can be approximated as stem water (Welp et al., 2008). Our data from plant sampling in the vicinity of the tall tower indicate a mean stem water oxygen isotope composition of $-7.0 \%$ in 2010 (Schultz, 2011).

Following the methodology of Kong et al. (2013), we estimated the recycling ratio of growing season precipitation $\left(f_{\mathrm{p}}\right)$ using the two-member mixing model approach:

$f_{\mathrm{p}}=\frac{d_{\mathrm{p}}-d_{\mathrm{adv}_{\mathrm{v}}}}{d_{\mathrm{E}}-d_{\mathrm{adv}_{\mathrm{v}}}}$

where $d_{\mathrm{p}}$ is the deuterium excess of precipitation, $d_{\mathrm{adv}_{\mathrm{v}}}$ is the deuterium excess of the advected moisture (approximated here by the large concentration footprint of the tall tower water vapor measurements at $185 \mathrm{~m}$ ), and $d_{\mathrm{E}}$ is the deuterium
Table 2. Precipitation isotope climatology. Precipitation isotope composition $\delta^{18} \mathrm{O}_{\mathrm{P}}$ and $\delta^{2} \mathrm{H}_{\mathrm{P}}(\%)$ are reported as amounted weighted values for the period 2010 to 2011. Deuterium excess of precipitation $\left(d_{\mathrm{P}}, \%\right.$ ) was calculated from the monthly fluxweighted values. All values in parentheses represent 1 standard deviation for the specified period.

\begin{tabular}{lrrr}
\hline Month & $\begin{array}{r}\delta^{18} \mathrm{OP}_{\mathrm{P}} \\
(\% \circ)\end{array}$ & $\begin{array}{r}\delta^{2} \mathrm{H}_{\mathrm{P}} \\
(\% \circ)\end{array}$ & $\begin{array}{r}d_{\mathrm{P}} \\
(\% o)\end{array}$ \\
\hline Jan & $-22.4(3.8)$ & $-173.2(34.3)$ & 6.0 \\
Feb & $-15.3(8.1)$ & $-113.7(64.6)$ & 8.7 \\
Mar & $-9.9(1.8)$ & $-64.7(15.7)$ & 14.5 \\
Apr & $-9.0(6.3)$ & $-65.2(51.3)$ & 6.8 \\
May & $-7.6(3.6)$ & $-51.0(25.9)$ & 9.8 \\
Jun & $-7.4(2.2)$ & $-47.5(20.1)$ & 11.7 \\
Jul & $-8.3(2.7)$ & $-58.3(18.6)$ & 8.1 \\
Aug & $-4.4(0.4)$ & $-24.9(4.6)$ & 10.3 \\
Sept & $-8.5(1.3)$ & $-56.7(10.4)$ & 11.3 \\
Oct & $-9.9(4.2)$ & $-62.7(32.4)$ & 16.5 \\
Nov & $-8.0(3.1)$ & $-43.5(19.3)$ & 20.5 \\
Dec & $-20.6(2.8)$ & $-153.0(23.9)$ & 11.8 \\
\hline Mean & -10.9 & -76.2 & 11.3 \\
\hline
\end{tabular}

excess of evaporation estimated from the flux ratio measurements at the tall tower.

\section{Results and discussion}

\subsection{Isotope composition of water vapor in the PBL}

Here we describe the climatology of the isotope composition of precipitation, water vapor, and surface evaporation as observed at the tall tower (Tables 1 and 2 and Figs. S2-S3). The mean oxygen and hydrogen isotope composition of precipitation (weighted by amount) was -10.9 and $-76.2 \%$, respectively, with a range of monthly means of 18.0 and $148.3 \%$, respectively. The isotope signature of precipitation showed peak enrichment of the heavier isotopes in August. The mean deuterium excess of precipitation was $11.3 \%$ with a range of $14.5 \%$. Peak values were observed during November. The oxygen and hydrogen isotope composition of water vapor $\left(\delta^{18} \mathrm{O}_{\mathrm{v}}\right.$ and $\left.\delta^{2} \mathrm{H}_{\mathrm{v}}\right)$ measured at the $185 \mathrm{~m}$ level had a mean annual value of -26.2 and $-176.0 \%$, respectively, with a range of monthly means of 24.3 and $165.7 \%$ o, respectively. The isotope signature of water vapor showed relatively strong enrichment of the heavier isotopes in July when the water vapor mixing ratio reached its maximum value. The mean annual deuterium excess $\left(d_{\mathrm{v}}\right)$ of water vapor was $28.4 \%$, with a range of $30.6 \%$. Deuterium excess of water vapor reached a minimum value in July.

The mean annual flux-weighted oxygen isotope ratio of surface evaporation $\left(\delta_{\mathrm{E}}=-13.3 \%\right.$ ) was in excellent agreement with the mean annual oxygen isotope ratio of the precipitation. There was strong seasonal variability in $\delta_{\mathrm{E}}$, with 

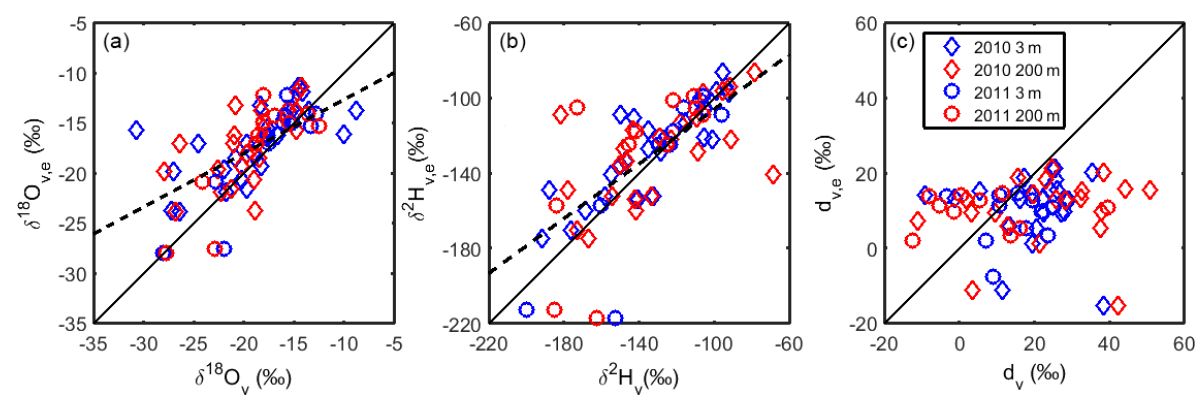

Figure 3. Comparison of (a) oxygen, (b) hydrogen, and (c) deuterium excess isotope composition of water vapor measured at 3 and $185 \mathrm{~m}$ compared to the theoretical values for water vapor in isotope equilibrium with precipitation (falling raindrops) during the 2010-2011 growing season. The solid lines show the $1: 1$ relation. The dashed lines show the best-fit linear regression.

a mean growing season value of $-6.2 \%$ over the 2010 to 2012 period, which was within the uncertainty of the oxygen isotope ratio estimates of evaporation and precipitation for the same period. The mean deuterium isotope composition of evaporation was $-77.8 \%$ and was relatively depleted compared to precipitation. Over relatively long timescales (seasonal) we would expect there to be isotope mass balance between the inputs (precipitation) and outputs (evaporation, runoff, drainage). The relatively good agreement observed here suggests that our atmospheric measurements provide a reasonable constraint on the isotope composition of evaporation. The effect of surface evaporation on the $\delta^{18} \mathrm{O}_{\mathrm{v}}$ and $\delta^{2} \mathrm{H}_{\mathrm{v}}$ of the PBL was estimated using the isoforcing approach. The oxygen isoforcing associated with evaporation was relatively strong from May to September with a mean value of $0.0068 \mathrm{~m} \mathrm{~s}^{-1} \%$ o (Table 1). The mean deuterium isoforcing was $0.0071 \mathrm{~m} \mathrm{~s}^{-1} \%$ o from May through August. These calculations show that surface evaporation acts to enrich PBL water vapor in the heavier isotopes. We hypothesize that this contributes to the highly enriched values of convective precipitation observed during the growing season (discussed further below).

The observations reported here are in broad agreement with previous work conducted near New Haven and Great Mountain Forest, Connecticut, United States (Lee et al., 2006). However, the continental location of Saint Paul, Minnesota, exhibits a larger seasonal amplitude of $\delta^{18} \mathrm{O}_{\mathrm{v}}$ associated with the Rayleigh distillation effect, and perhaps, higher rates of evaporation and isoforcing from crops during the middle of the growing period.

The observed isotope ratios in water vapor, $\delta^{18} \mathrm{O}_{\mathrm{v}}$ and $\delta^{2} \mathrm{H}_{\mathrm{v}}$, measured at 3 and $185 \mathrm{~m}$, were compared with those derived from the isotope equilibrium theory $\left(\delta^{18} \mathrm{O}_{\mathrm{v}, \mathrm{e}}\right.$ and $\delta^{2} \mathrm{H}_{\mathrm{v}, \mathrm{e}}$ ) for individual precipitation events to gain insights regarding the validity of the tall tower observations and the isotope fractionation of water vapor in the PBL. Figure 3 shows results for 35 rain events from the 2010 to 2011 growing seasons. Overall, there was good agreement between the measured isotope ratios in water vapor compared to those predicted from the equilibrium theory. The mean measured $\delta^{18} \mathrm{O}_{\mathrm{v}}$ was lower by $1.4 \pm 0.4 \%$ (uncertainty reported as the standard error) relative to the rain event $\delta^{18} \mathrm{O}_{\mathrm{v}, \mathrm{e}}$ values. The linear regression shown in Fig. 3a $\left(y=0.54 x-7.3, r^{2}=0.42, p<0.001\right)$ supports that the derived equilibrium vapor values were modestly correlated $(r=0.65)$ with the observed vapor values. A similar relation was observed for $\delta^{2} \mathrm{H}_{\mathrm{v}}\left(y=0.73 x-33.3, r^{2}=0.50\right.$, $p<0.001)$. The mean measured $\delta^{2} \mathrm{H}_{\mathrm{v}}$ in water vapor was lower by $2.9 \pm 2.3 \%$ relative to the rainwater $\delta^{2} \mathrm{H}_{\mathrm{v}, \mathrm{e}}$ values. These differences were magnified when calculating deuterium excess $(d)$ (Fig. 3c). Derived equilibrium vapor $d_{\mathrm{v}, \mathrm{e}}$ values were lower by $7.8 \pm 3.1 \%$.

It is well established that partial raindrop evaporation occurs below the cloud base because atmospheric humidity rarely achieves saturation through the entire depth over the course of an event (Lee et al., 2006). Partial raindrop evaporation acts to enrich the raindrop in heavy isotopes as the lighter isotopes preferentially escape to the atmosphere due to kinetic fractionation (Stewart, 1975; Jacob and Sonntag, 1991). This is especially true for short-duration and lowmagnitude convective rain events (Yu et al., 2006; Tian et al., 2007; Wen et al., 2010; Huang and Wen, 2014; Aemisegger et al., 2015). Worden et al. (2007) concluded that 20 to $50 \%$ of rainfall evaporates near convective clouds over tropical locations, leading to strong isotopic signatures as observed from the Tropospheric Emission Spectrometer (TES). Further, recent work by Aemisegger et al. (2015) has pointed out that the vertical structure of a cold front will tend to produce these observed differences, as warm air and water vapor that is relatively enriched in the heavier isotopes is lifted from the surface (warm sector), and as colder air and water vapor that is relatively depleted in the heavier isotopes is sinking and influencing the surface observations.

The results shown here are similar to other field-based studies. Lee et al. (2006) concluded that observed $\delta^{18} \mathrm{O}_{\mathrm{v}}$ in water vapor and that derived from the equilibrium theory for a site in New Haven, Connecticut, United States, agreed to within -2.5 to $1.5 \%$. Wen et al. (2010) reported that values for a site in Beijing, China, were within $-0.8 \pm 1.9$, $1.9 \pm 9.9$, and $7.7 \pm 8.3 \%$ for $\delta^{18} \mathrm{O}_{\mathrm{v}}, \delta^{2} \mathrm{H}_{\mathrm{v}}$, and $d_{\mathrm{v}}$ (uncer- 
tainty reported as 1 standard deviation), respectively. Precipitation data collected from 2006 to 2011 near the tall tower site also support that isotope ratios in precipitation tend to be more enriched in heavy isotopes for small rainfall events. Overall, the difference between observed isotope ratios in water vapor and the equilibrium values is small and partial raindrop evaporation likely contributes to this observed difference.

\subsection{Controls on isotope composition of water vapor}

The relation between $\delta^{18} \mathrm{O}_{\mathrm{v}}$ and water vapor mixing ratio measured at $185 \mathrm{~m}$ (2010 to 2012) is compared with the three isotope models (RM1, RM2, and EM1 defined above) for different time periods (Fig. 4) to gain further insights regarding the dominant processes influencing the tall tower observations. Given the large number of hourly water vapor observations, these data are displayed using a smoothed histogram technique (Eilers and Goeman, 2004). On an annual basis, the upper bound is defined by the simple two-source mixing models (EM1 and BestFitEM1) (Fig. 4a). A lower bound is defined by RM2 (a Rayleigh model that allows for a rainout fraction of $30 \%$ ). Assuming a simple closed system, RM1 provides an intermediate fit, and its curvature, relative to the data density contours, illustrates that Rayleigh processes have a predominant influence on the oxygen isotope composition of the PBL vapor.

Given the initial conditions of the air mass, described above, the best fit Rayleigh model yielded an $r^{2}$ of 0.76 and an equilibrium fractionation factor of $\alpha=1.0103(p<$ 0.001 ) (equivalent to a condensation temperature of $15^{\circ} \mathrm{C}$ ). Lee et al. (2006) also reported a large warm bias in the condensation temperature when applying the same type of model to their annual data set in New Haven, Connecticut, United States. The best fit Keeling mixing model yielded an $r^{2}$ of 0.37 and a very realistic estimate of the oxygen isotope composition of surface evaporation $(-7.4 \%, p<$ 0.001) (Fig. 4a). Although the process of surface evaporation explained much less of the total variation in PBL vapor compared to the Rayleigh model, the relatively high coefficient of determination and statistical significance of the best fit parameters provides some evidence that surface evaporation within the region strongly modifies the oxygen isotope composition of vapor arriving at the tall tower.

Closer examination of the growing season data (Fig. 4b) indicates that the rainout fraction may exceed $f=30 \%$ as evidenced by the relatively large isotope depletion that occurs for water vapor mixing ratios between 15 and $20 \mathrm{mmol} \mathrm{mol}^{-1}$. It is also possible that these observations are associated with smaller convective summertime rain events when partial raindrop evaporation is favorable (Yu et al., 2006; Tian et al., 2007; Wen et al., 2010; Huang and Wen, 2014). The best fit Rayleigh and Keeling models explained 59 and $50 \%$ of the variation, respectively. During the nongrowing season the best fit Rayleigh and Keeling models ex- plained 72 and $29 \%$ of the variation, respectively. The density plot shows that the curvature of the data is similar to the Rayleigh model; however, the highest data density region (see bright yellow shaded contours) indicates a departure from this curvature that is consistent with evaporation effects.

The tall tower vapor data differ substantially from the GMWL and the Local Meteoric Water Line (LMWL, $\delta^{2} \mathrm{H}=$ $\left.7.8 \delta^{18} \mathrm{O}+6.9\right)$ (Fig. 4d). The growing season PBL Water Vapor Line (WVL, $\delta^{2} \mathrm{H}=6.2 \delta^{18} \mathrm{O}-15.3, r^{2}=0.86, p<$ 0.001 ), with a slope much less than 8 , implies a relatively strong influence of evaporation. Analyses of local leaf water from agricultural plants $\left(\delta^{2} \mathrm{H}=2.7 \delta^{18} \mathrm{O}-37.1\right)$ and the soil $\left(\delta^{2} \mathrm{H}=5.3 \delta^{18} \mathrm{O}-21.6\right)$ provide strong evidence that evaporation was an important source of the PBL vapor. If the isotope composition of water vapor within the region were determined primarily by precipitation inputs (i.e., if the vapor were in isotope equilibrium with precipitation), then the $\delta^{2} \mathrm{H}-\delta^{18} \mathrm{O}$ relation would be equal to the LMWL. If we make this assumption, a growing season water vapor equilibrium line can be calculated $\left(\mathrm{WVL}_{\mathrm{eq}}=\delta^{2} \mathrm{H}=7.4 \delta^{18} \mathrm{O}-0.18\right)$. In this case, the slope and intercept of the WVL and WVL eq relations are statistically different $(p<0.05$ and $p<0.1)$ and demonstrate that the isotope composition of water vapor is not simply derived from the precipitation, but is modified by other processes. Welp et al. (2008) came to a similar conclusion for field-scale measurements conducted within a few kilometers of the tall tower during the summer of 2006.

While the GMWL parameter values are determined primarily by the Rayleigh distillation effect, deuterium excess values $\left(d_{\mathrm{v}}=\delta^{2} \mathrm{H}-8 \delta^{18} \mathrm{O}\right)$ in water vapor are largely governed by non-Rayleigh distillation processes (Gat and Airey, 2006). Here, we observed large positive $d_{\mathrm{v}}$ in vapor for all months. The mean annual values were $28.4 \%$ (Table 1) with mean monthly values ( $>35 \%$ ) observed from November through January. The mean growing season $d_{\mathrm{v}}$ value was $22.3 \%$. The mean monthly values showed negative relations with water vapor mixing ratio $(y=-0.98 x+43.6$, $\left.r^{2}=0.55\right)$, air temperature $\left(y=-0.83 x+41.0, r^{2}=0.52\right)$, and precipitation amount $\left(y=-0.09 x+39.3, r^{2}=0.37\right)$, and a very weak positive relation with relative humidity $\left(y=1.28 x-68.5, r^{2}=0.08\right)$.

Based on an analysis of water vapor $d_{\mathrm{v}}$ from several midlatitude locations, Welp et al. (2012) found that the diurnal variability was likely controlled by two dominant processes, including plant transpiration and PBL water vapor entrainment. Lai and Ehleringer (2011) also observed a strong influence of PBL entrainment on the early morning variations in $d_{\mathrm{v}}$ in a Pacific west coast Douglas fir forest. Huang and Wen (2014) have also examined the factors controlling $d_{\mathrm{v}}$ over cropland in Zhangye, northwest China. In their analyses, they showed that variation in the deuterium excess of evaporation explained $94 \%$ of the variation in daytime water vapor $d_{\mathrm{v}}$, implying that at some locations water vapor $d_{\mathrm{v}}$ is an excellent tracer of surface evaporation. The recent work 

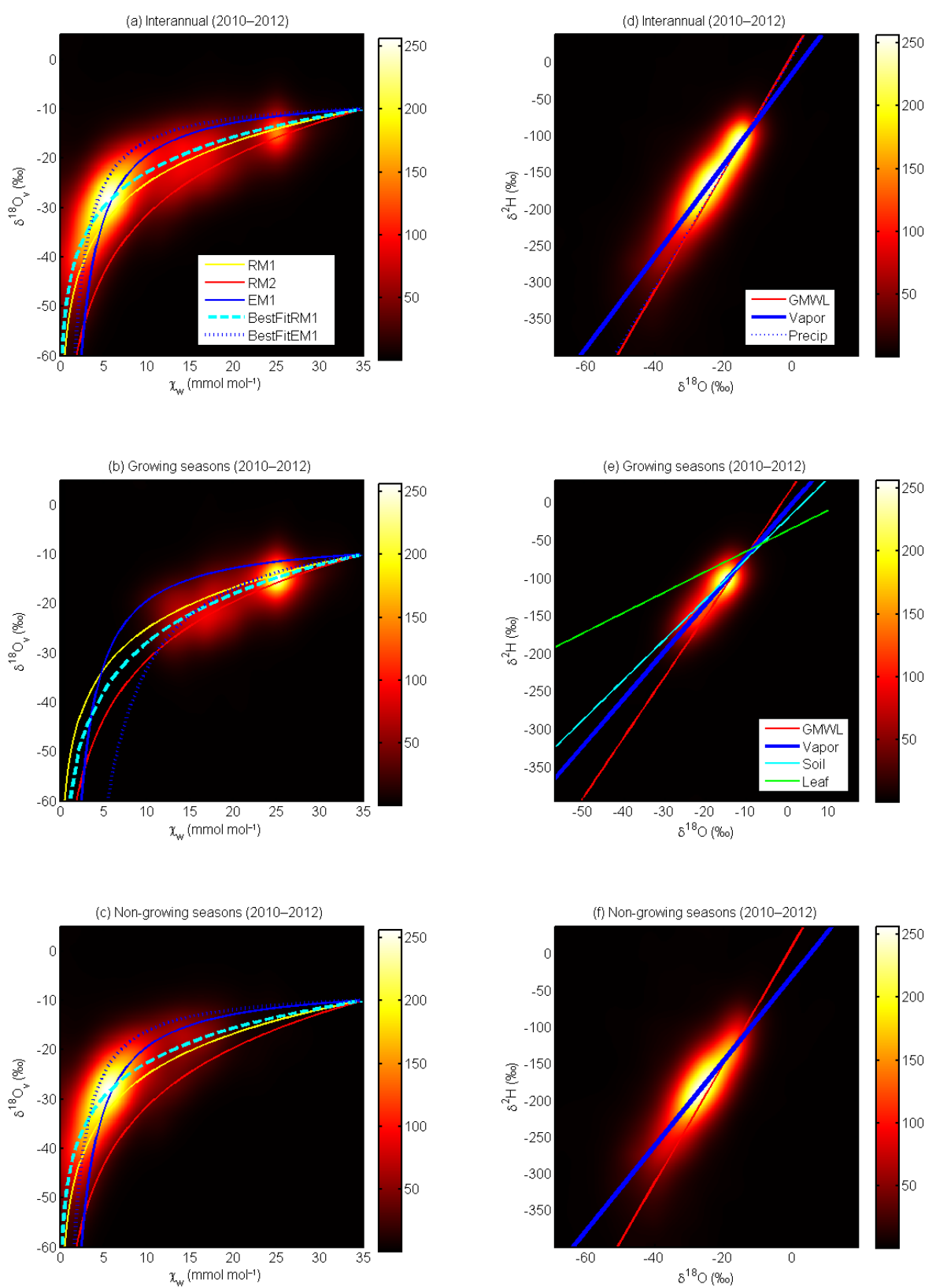

Figure 4. Smoothed histogram plots of oxygen and deuterium isotope ratios in water vapor from 2010 to 2012 . Panels (a-c) illustrate oxygen isotope ratios in water vapor as a function of water vapor mixing ratio measured at a height of $185 \mathrm{~m}$ on the University of Minnesota tall tower for (a) all years, (b) the growing season, and (c) the non-growing season. Panels (d-f) show isotope ratios in water vapor, soil water, and local leaf water plotted in $\delta^{18} \mathrm{O}-\delta^{2} \mathrm{H}$ space for (d) all years, (e) the growing season, and (f) the non-growing season. The lines represent different models and parametrizations (RM1, RM2, and EM1) as described in the text. Color bars indicate the number of observations.

of Zhao et al. (2014) suggests that plant transpiration has a dominant influence on vapor $d_{\mathrm{v}}$ on diurnal timescales. At the longer timescales (monthly) examined here we expect that the variability and departure from the GMWL is influenced by synoptic conditions and air mass trajectories with strong modification by surface evaporation from within the region. For instance, the large $d_{\mathrm{v}}$ values observed during the nongrowing season, especially during November and December, suggest the important role of near-surface water evaporation (i.e., large kinetic fractionation effects associated with evaporation) (Gat, 1996) within the region and probably reflect the dominant contributions of evaporation from bare agricultural soils and the Great Lakes, of which the latter reach peak evaporation rates in late fall and early winter (Blanken et al., 2011). As noted by Aemisegger et al. (2015), the ability to simulate $d_{\mathrm{v}}$ is highly sensitive to the isotope fractionation 



Figure 5. Wavelet coherence analysis of the oxygen isotope ratio of water vapor $\left(\delta^{18} \mathrm{O}_{\mathrm{v}}\right)$ for August 2010. Hourly observations of water vapor mixing ratio and oxygen isotope ratio from the tall tower $185 \mathrm{~m}$ sample level (a). Wavelet coherence of modeled oxygen isotope ratios using the Rayleigh model (described in the text) vs. the observations (b). Wavelet coherence of time derivative of $\delta^{18} \mathrm{O}_{\mathrm{v}}$ vs. evaporation isoforcing integrated over the depth of the PBL (c). Wavelet coherence of time derivative of $\delta^{18} \mathrm{O}_{\mathrm{v}}$ vs. PBL growth (d). The color bar represents the local correlation coefficients in time-frequency space. The period is shown in hours. The black arrows represent the phase angle relationship between the variables. Arrows pointing east and west show signals that are in perfect phase and antiphase, respectively. Arrows pointing north show that variable 1 leads variable 2 (defined in figure panel titles) by a phase shift of 90 degrees.

during soil evaporation. During the main growing season, $d_{\mathrm{v}}$, was less positive because plant transpiration is a nondiscriminating process under equilibrium conditions (Zhao et al., 2014) and represents a substantial fraction of surface evaporation.

To further explore the influence of Rayleigh distillation, evaporation, and PBL growth processes on the isotope composition of the PBL, we performed cross-wavelet multivariate analyses for near-continuous time series observed in $\mathrm{Au}$ gust 2010 (Figs. 5 and 6). Analyses for the Rayleigh modeled (model RM2 from Fig. 4) oxygen isotope composition of water vapor $\left(\delta^{18} \mathrm{O}_{\mathrm{R}}\right)$ vs. the tall tower $\delta^{18} \mathrm{O}_{\mathrm{v}}$ observations (Fig. 5) demonstrate relatively strong in-phase coherence through the month of August 2010 across a broad range of periods. It is interesting to note when the Rayleigh relation fails to describe the observations. For example, at periods greater than $64 \mathrm{~h}$ and periods less than $8 \mathrm{~h}$ there are numerous days in August 2010 when the Rayleigh relation and observations show little or no coherence. Identifying the exact mechanisms that account for these discrepancies is challenging because many meteorological processes operating in the PBL are not independent (i.e., there is feedback between surface evaporation and PBL growth; McNaughton and Spriggs,
1986). For example, Fig. 6 shows there is strong coherence with a phase lag of about $3 \mathrm{~h}$ (90 degrees) between evaporation and PBL growth rate for diurnal cycles (periods ranging from 8 to $32 \mathrm{~h}$ ) for nearly the entire month of August 2010. Figure 5 also shows the wavelet coherence between the evaporation isoforcing and the time derivative of $\delta^{18} \mathrm{O}_{\mathrm{v}}$ as well as the PBL growth rate vs. the time derivative of $\delta^{18} \mathrm{O}_{\mathrm{v}}$. These analyses show that there are a number of more isolated periods when there is strong coherence, confirming that both surface evaporation and PBL growth are key forcing factors (Lee et al., 2012).

Similar analyses were also performed to examine the behavior of $d_{\mathrm{v}}$ (Fig. 6). These analyses reveal the influence of synoptic/air mass effects and PBL effects on $d_{\mathrm{v}}$. For example, similar coherence was observed for wind direction vs. $d_{\mathrm{v}}$ and water vapor mixing ratio vs. $d_{\mathrm{v}}$. The coherence was significant for periods ranging from 100 to $256 \mathrm{~h}$ or 4 to 10 days implying the importance of synoptic-scale air mass back trajectories. The effects of PBL growth and surface evaporation on $d_{\mathrm{v}}$ clearly operate at different periods through the time series. The effects of PBL growth rate showed significant coherence at diurnal scales (periods ranging from 4 to $64 \mathrm{~h}$ ), while the evaporation showed significant coherence with $d_{\mathrm{v}}$ 

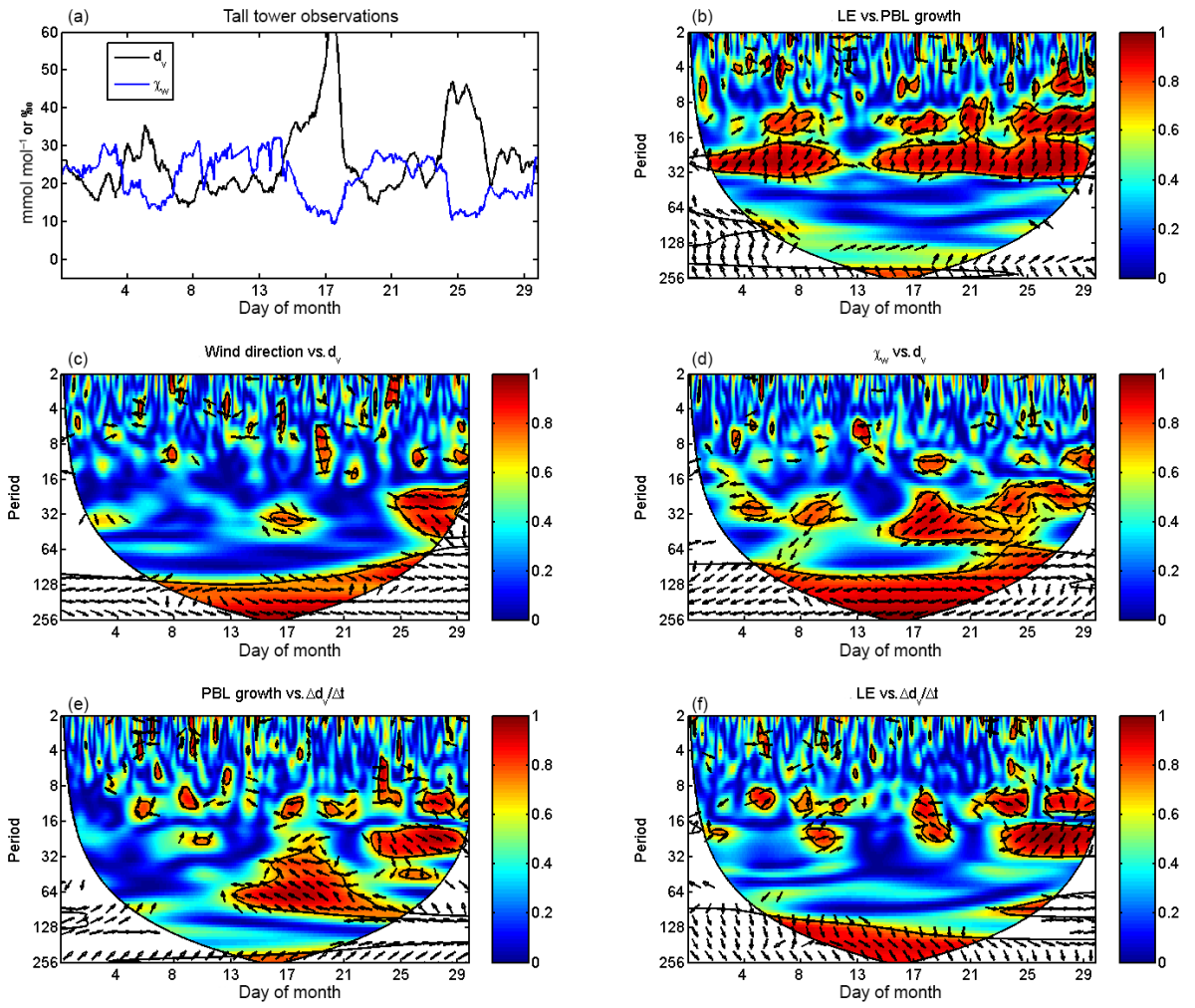

Figure 6. Wavelet coherence analysis of deuterium excess $\left(d_{x}\right)$ for August 2010. Hourly observations of water vapor mixing ratio and deuterium excess from the tall tower $185 \mathrm{~m}$ sample level (a). Wavelet coherence of evaporation vs. PBL growth (b). Wavelet coherence of wind direction vs. PBL growth (c). Wavelet coherence of water vapor mixing ratio vs. deuterium excess (d). Wavelet coherence of PBL growth vs. the time derivative of deuterium excess (e). Wavelet coherence of evaporation vs. the time derivative of deuterium excess (f). The color bar represents the local correlation coefficients in time-frequency space. The period is shown in hours. The black arrows represent the phase angle relationship between the variables. Arrows pointing east and west show signals that are in perfect phase and antiphase, respectively. Arrows pointing north show that variable 1 leads variable 2 (defined in figure titles) by a phase shift of 90 degrees.

on diurnal ( 8 to $32 \mathrm{~h}$ ) and synoptic (128 to $256 \mathrm{~h})$ scales. In many cases, the phase lag between evaporation and $d_{\mathrm{v}}$ implies that evaporation is leading the change in $d_{\mathrm{v}}$.

To probe this further, we focus our attention on the evaporation isoforcing (oxygen isotope) characteristics (Fig. 7). Using the WRF-modeled PBL heights we estimated the evaporation isoforcing effect over the depth of the PBL for each hour. The time derivative of the evaporation isoforcing was then compared to the time derivative of $\delta^{18} \mathrm{O}_{\mathrm{v}}$. The time series and distributions of these derivatives show that they are of similar magnitude. Here, the mean absolute values of both distributions indicate that evaporation can account for about $53 \%$ of the variation in $\delta^{18} \mathrm{O}_{\mathrm{v}}$ for August 2010, implying that surface evaporation is a dominant controlling factor.

A case study of high PBL water vapor concentration (defined here as $\geq 30 \mathrm{mmol} \mathrm{mol}^{-1}$ ) was carried out to further examine the underlying controlling factors. The extreme event of 14 July 2010 had a maximum dew point temperature of $26^{\circ} \mathrm{C}$ at 13:00 LST. Local water vapor mixing ratios increased from about 22 to $39 \mathrm{mmol} \mathrm{mol}^{-1}$ over the $24 \mathrm{~h}$ period. The locally measured and modeled vapor fluxes were very high, ranging up to $10.6 \mathrm{mmol} \mathrm{m}^{-2} \mathrm{~s}^{-1}$ near midday. Over a $12 \mathrm{~h}$ period, starting at midnight, we calculated the change in water vapor concentration within the PBL that was associated with the average rate of evaporation for the tall tower domain (i.e., $80 \times 80 \mathrm{~km}$ inner domain). These calculations indicate that evaporation could account for about $8.4 \mathrm{mmol} \mathrm{mol}^{-1}$ change (about $83 \%$ of the observed variation) in the PBL water vapor concentration. The WRF-STILT source footprint analyses are shown for this case in Fig. 8. These results illustrate that the vapor source was associated with NNE to ESE flow the day before (13 July 2010), with flow switching to WNW the day after (15 July 2010) the extreme event. The highest water vapor concentrations were observed on 14 July 2010 when the flow was southerly before the passage of a cold front. The source footprint intensity was greatest in Minnesota, Iowa, and Indiana and was dominated by agricultural sources $(59 \%)$.

Additional evidence is provided by the tall tower isotope data and isoforcing (oxygen isotope) calculations. The tall tower observations during this period indicate that the $\delta^{18} \mathrm{O}$ of water vapor increased steadily from about -18 to $-13 \%$. 

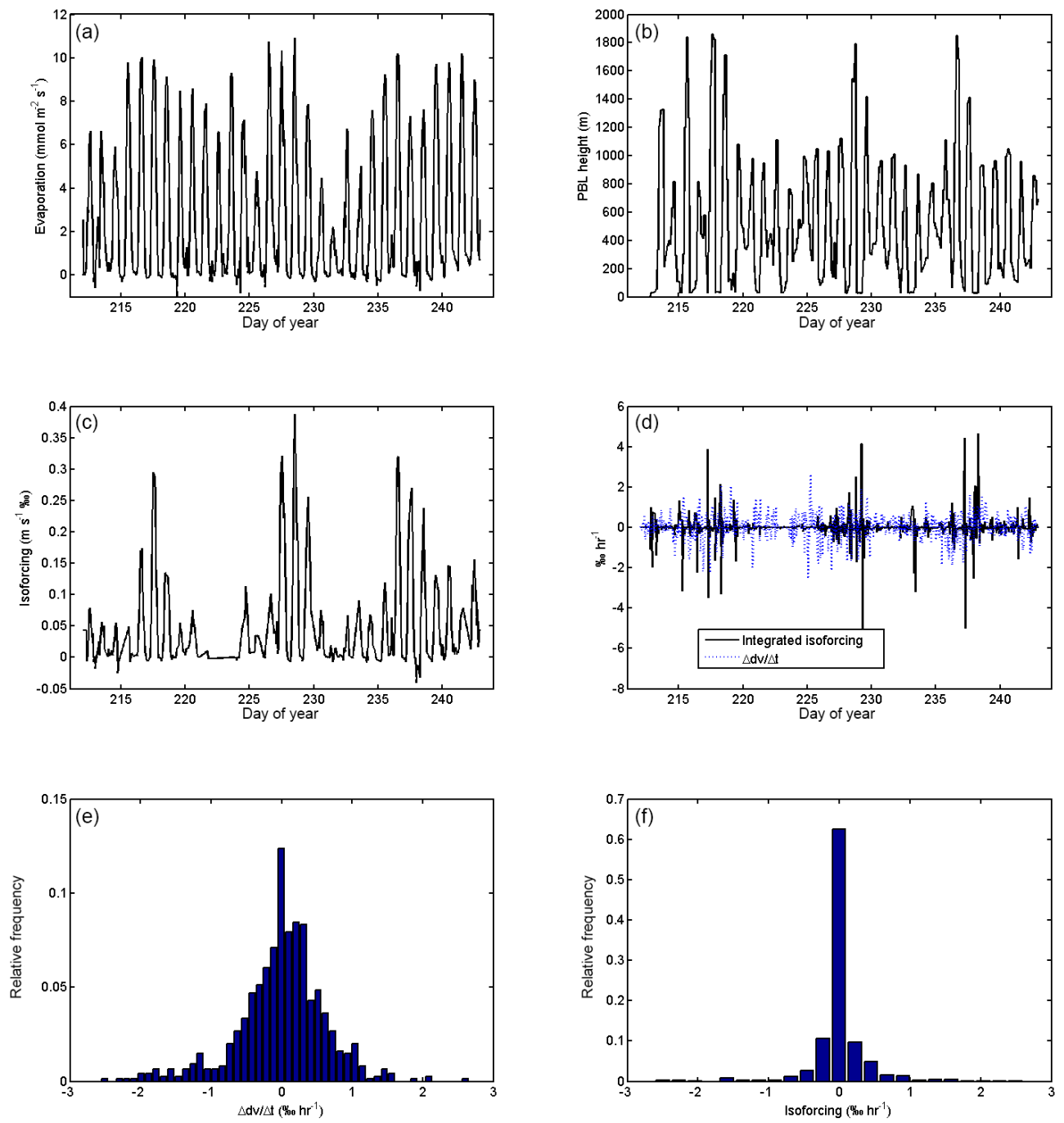

Figure 7. The influence of evaporation isoforcing (oxygen isotopes) on the oxygen isotope composition of PBL water vapor during August 2010. Hourly evaporation ( $\mathrm{mmol} \mathrm{m}^{-2} \mathrm{~s}^{-1}$ ) measured by the eddy covariance approach over agricultural crops located within the footprint of the University of Minnesota tall tower (a). PBL height simulated using WRF3.5 for the tall tower location (b). Tall tower evaporation isoforcing calculation (c). Evaporation isoforcing calculation integrated with respect to PBL height and compared to the time derivative of the oxygen isotope ratio of water vapor $\left(\delta^{18} \mathrm{O}_{\mathrm{v}}\right)(\mathbf{d})$. Normalized frequency distribution of the time derivative of $\delta^{18} \mathrm{O}_{\mathrm{v}}$ observations $(\mathbf{e})$. Normalized frequency distribution of the integrated evaporation isoforcing calculations (f).
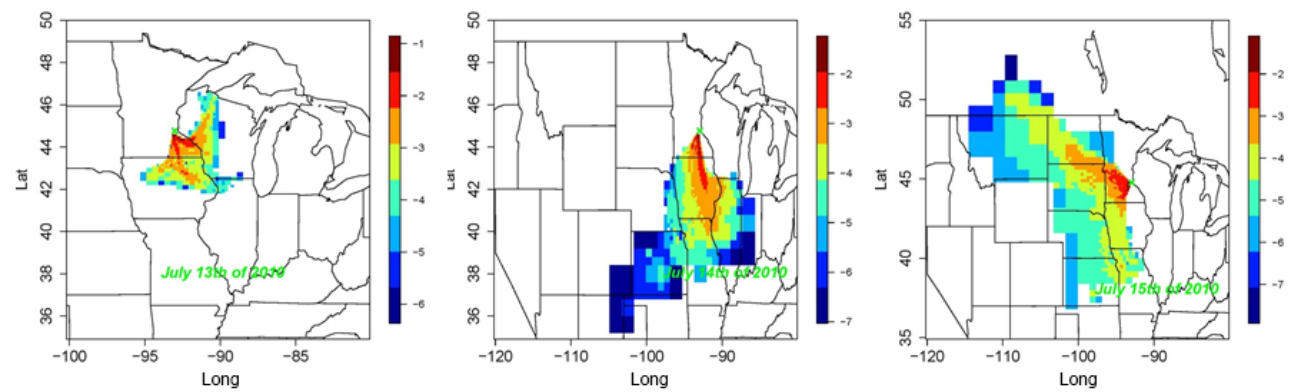

Figure 8. Source footprint analysis of planetary boundary layer water vapor arriving at the University of Minnesota tall tower based on the Stochastic Time-Inverted Lagrangian Transport (STILT). These data and analyses represent a high dew point event that occurred on 14 July 2010 . 
Further, for the same $12 \mathrm{~h}$ period as described above, the instantaneous $I_{F}$ averaged $0.08 \mathrm{~m} \mathrm{~s}^{-1} \%$ o. Therefore, over the $12 \mathrm{~h}$ period, the $I_{F}$ associated with evaporation accounted for a $3.8 \%$ variation in the PBL vapor and about $61 \%$ of the observed variation. Thus, multiple lines of evidence support that this extreme dew point event was substantially enhanced by local/regional evaporation. These observations also support the general relationship described below in Fig. 9, indicating that a high fraction of the PBL water vapor was generated locally.

Although other approaches have been used to infer the impact of the US Corn Belt (Changnon et al., 2003) on regional humidity, the combined data, and the analytical and modeling approaches used here offer a unique and more direct quantification. The higher amplitude of crop transpiration rates during the middle of the growing season (Fig. S4) indicate that summertime humidity can be significantly amplified by crops and may, therefore, enhance convective precipitation.

\subsection{Evaporation contribution to PBL vapor and precipitation}

WRF modeling and isotope mixing model analyses were used to help constrain the contribution of regional evaporation to PBL water vapor. The mean (2008-2011) growing season latent heat flux densities for each land use class within the study domain (i.e., the innermost domain of $80 \times 80 \mathrm{~km}$ ) were approximately 25 (0.57), 114 (2.6), 119 (2.7), 112 (2.5), 130 (2.9), and $14(0.32) \mathrm{W} \mathrm{m}^{-2}\left(\mathrm{mmol} \mathrm{m}^{-2} \mathrm{~s}^{-1}\right)$ for urban, dryland crops, dryland crops/grasslands, grasslands, evergreen needle leaf forest, and lakes, respectively (Fig. S5). The area-weighted contribution of each land use type to the total evaporative flux for the study domain was dominated by dryland crop (58\%) and dryland crops/grasslands (42\%), respectively. The growing season contributions to evaporation for all other land use types were insignificant according to the WRF-NOAH modeling (and given the spatial resolution for the domain) over the period 2008 to 2011.

The WRF land use evaporation analysis was combined with the oxygen isotope observations using a simple mixing model to help constrain the relative contributions of evaporation to PBL water vapor. Since the area-weighted flux densities indicate that evaporation is dominated by the agricultural land use, we make use of the key isotope signals from the agricultural component and a simple two-end-member isotope mixing model. Figure 9 shows the histogram of the fraction of local vapor $\left(f_{\mathrm{v}}\right)$, estimated using the oxygen isotope mixing model for the daytime for June through August. The median $f_{\mathrm{v}}$ was $34 \%$ for the 2010-2012 growing seasons. The fraction of local vapor is also plotted as a function of the PBL water vapor mixing ratio observed at $185 \mathrm{~m}$. The PBL vapor partitioning followed a saturation-type function $\left(f_{\mathrm{v}}=0.66 \chi_{\mathrm{w}} /\left(14.7+\chi_{\mathrm{w}}\right), r^{2}=0.18, p<0.001\right)$. This relation indicates that the fraction of local water vapor increases asymptotically with water vapor mixing ratio. As expected,
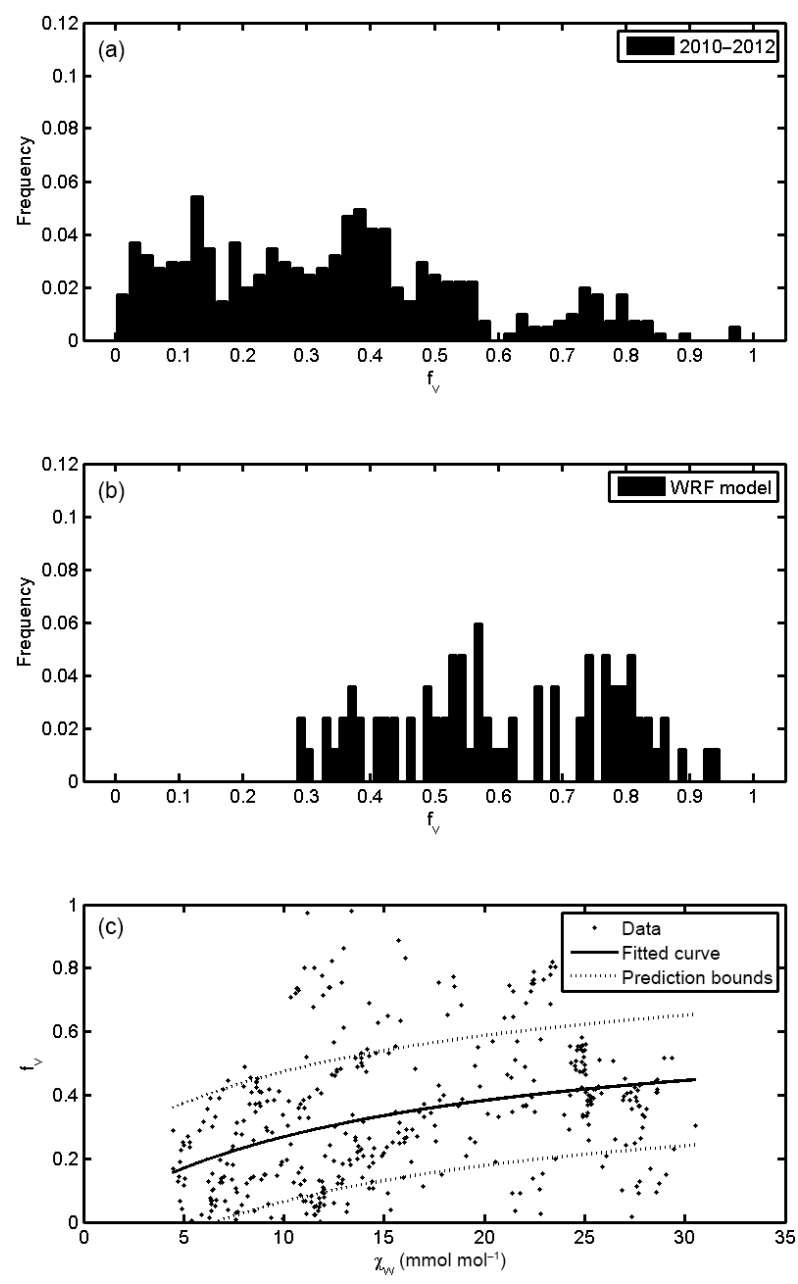

Figure 9. Normalized frequency distributions of PBL water vapor partitioning $\left(f_{\mathrm{V}}\right)$ for June to August 2010-2012 (a) and normalized frequency distribution for estimates derived from the Weather Research and Forecasting (WRF3.5) model simulations for JuneAugust 2010 (b). Here, the average daytime values represent the fraction of water vapor in the PBL derived from local evaporation evaluated under the following conditions, evaporation $>0$, and $-u \mathrm{~d} X / \mathrm{d} x>0$ and $-v \mathrm{~d} X / \mathrm{d} y>0$. Panel (c) shows the fraction of evaporated vapor contained in the planetary boundary layer as a function of total water vapor mixing ratio. The prediction bounds represent $1 \sigma$.

small changes in local evaporation can have a stronger effect on the fraction of water vapor in the PBL when mixing ratios are relatively low $\left(<10 \mathrm{mmol} \mathrm{mol}^{-1}\right)$. At mixing ratios of $25 \mathrm{mmol} \mathrm{mol}^{-1}$, this relation implies that the locally generated vapor from evaporation accounts for about $42 \%$ of water vapor in the PBL. However, the uncertainty is very large with prediction bounds, indicating a $1 \sigma$ uncertainty range of 21 to $62 \%$. Also shown in Fig. 9 is the fraction of PBL water vapor derived from evaporation as simulated by WRF for June to August 2010. The WRF simulations indicate that on average daytime evaporation accounted 
for about $61 \pm 18 \%$ of the PBL water vapor. The median water vapor mixing ratios in 2010, 2011, and 2012 were 19.7, 18.1 , and $15.9 \mathrm{mmol} \mathrm{mol}^{-1}$, respectively, indicating that the locally generated vapor accounted for 38,36 , and $34 \%$ of the signal. Based on global analyses, best estimates indicate that approximately $40000 \mathrm{~km}^{3}$ of water vapor are transported to the continents each year, with evaporation from terrestrial ecosystems accounting for $73000 \mathrm{~km}^{3}$ (Trenberth et al., 2007b; Trenberth and Asrar, 2014). This global ratio of oceanic advection to terrestrial evaporation implies that $65 \%$ of the vapor signal over the continents is derived from evaporation and is considerably larger than our median values obtained for the PBL in the upper Midwest, United States.

The different estimates of $\delta_{\mathrm{E}}$ provide a way of evaluating the relative uncertainty of the mixing model approach. For example, a change in the mean flux-weighted isotope composition of evaporation by $+3 \%$ would shift the relations observed in Fig. 9 lower. At mixing ratios of $25 \mathrm{mmol} \mathrm{mol}^{-1}$ the local contributions to PBL water vapor would be lower by approximately $6 \%$. Further, if the isotope composition of the background vapor were $3 \%$ o lower, the sensitivity of the partitioning approach to the background estimate of the isotope composition of vapor would shift the relation observed in Fig. 9 higher. At mixing ratios of $25 \mathrm{mmol} \mathrm{mol}^{-1}$ the local contributions to PBL water vapor would be higher by approximately $2 \%$. This sensitivity is lower compared to changes in $\delta_{\mathrm{E}}$ because $\delta_{\mathrm{b}}$ appears in the numerator and denominator of Eq. (10).

As described above, the isotope composition of the annual (non-growing and growing season) precipitation for the period 2006-2011 closely followed the GMWL. Here we examine in more detail the isotope composition of precipitation during the growing season to gain new insights regarding source origin and regional recycling. As discussed by Trenberth and Asrar (2014), numerical models tend to overestimate local-scale moisture recycling; therefore, additional constraints provided by empirical data may be used to help diagnose such biases.

Examination of growing season (1 May to 31 August) precipitation in $\delta^{2} \mathrm{H}-\delta^{18} \mathrm{O}$ space indicated a near-identical slope (8.04) to the GMWL, and a smaller intercept (8.3) with $r^{2}=0.94$. Figure 10 shows that $f_{\mathrm{p}}$ ranged from close to 0 to $96 \%$ over the period, with a median value of $26 \%$. Interestingly, Fig. 10 indicates that from DOY 121 to DOY $180, f_{\mathrm{p}}$ was approximately $10 \%$ and increased significantly to $54 \%$ for the period DOY 180 to DOY 240. This step change is coincident with high land surface evaporation during this period of peak growth for the agricultural region. Further, it has been shown that the Great Plains low-level jet (GPLLJ) has a strong influence on vapor transport into the region and can have an important effect on regional water recycling (Harding, 2014). Based on the model data presented by Harding (2014) (his Table 2.5, the 100 strongest warm season precipitation events in the North Central U.S.) the median recycling ratio was $12.1 \%$ with a range of 4.2 to $34.6 \%$. We
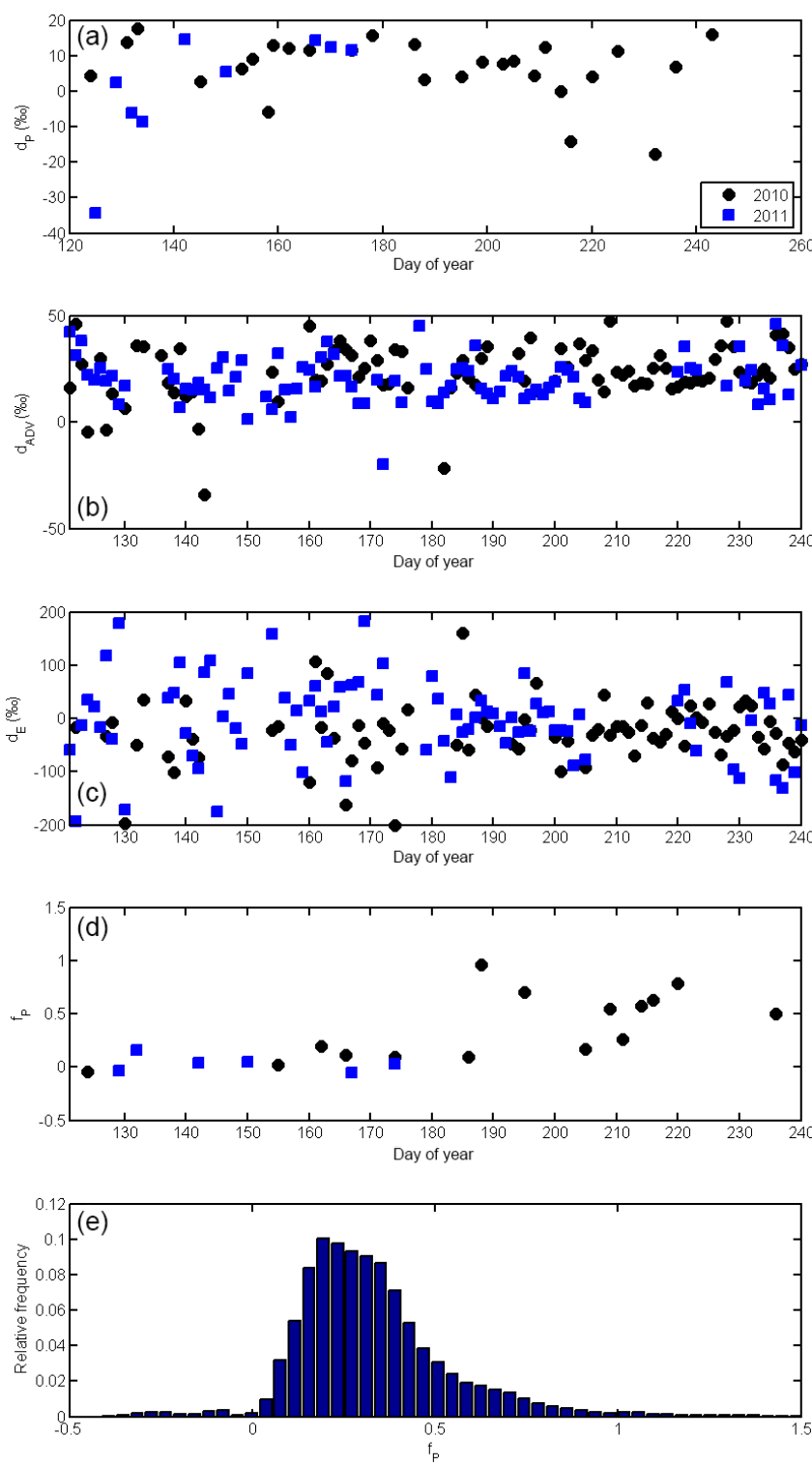

Figure 10. Precipitation recycling ratio estimated using a simple deuterium excess mixing model. The panels from top to bottom represent (a) deuterium excess in precipitation; (b) deuterium excess of water vapor measured at $185 \mathrm{~m}$ on the tall tower (i.e., approximation of the advection term); (c) deuterium excess of evapotranspiration determined from the tall tower flux ratio method; (d) precipitation recycling ratio; (e) estimate of growing season precipitation recycling ratio for 2006-2011 based on precipitation and tall tower isotope data and a Monte Carlo simulation.

re-examined these data and found that the recycling ratio increased as the GPLLJ weakened $\left(y=-0.099 x+0.18, r^{2}=\right.$ 0.18 ), indicating that local evaporation becomes increasingly important as long-distant transport from the Gulf of Mexico weakens.

Because the $d_{\mathrm{adv}}$ and $d_{\mathrm{E}}$ are highly variable and subject to considerable noise, we performed a Monte Carlo simulation 
to provide a more robust growing season estimate of $f_{\mathrm{p}}$ based on the observed precipitation data from 2006 to 2011 at the tall tower. Here we use the Monte Carlo approach to select values of $d_{\mathrm{adv}}$ and $d_{\mathrm{E}}$ based on the tall tower observations from 2010 to 2011. The Monte Carlo method selected median values within the $95 \%$ confidence intervals. One thousand simulations were performed to evaluate Eq. (8) for each precipitation event from 2006 to 2011. Figure 10 shows the frequency distribution of values. Notice that we did not filter any of the $f_{\mathrm{p}}$ estimates; therefore, there are values that fall outside of the realistic range. Overall, we find that the growing season $f_{\mathrm{p}}$ value was $31 \%$, indicating that terrestrial evaporation significantly enhances the warm season precipitation.

Atmospheric water recycling is expected to be strongly linked to climate change with amplification anticipated during wet periods (Vallet-Coulomb et al., 2008). Bosilovich and Schubert (2002) used a general circulation model with water vapor tracers to follow their transport through the model atmosphere. They concluded that $14 \%$ of the water precipitated within the US Midwest was derived from local evaporation. Zangvil et al. (2004) restricted their numerical modeling analyses to the growing season and US Corn Belt and estimated that the water recycling index ranged up to $45 \%$. In fact, they found that seasonal and monthly analyses masked the importance of recycling on short (daily) timescales. As discussed by Trenberth (1998) the calculation of water recycling using numerical models is scaledependent. In his analysis, annual moisture recycling in the Mississippi Basin was on the order of 7 and up to $21 \%$ during the summertime when using a length scale of $1800 \mathrm{~km}$. Further, Eltahir and Bras (1996) also suggest that summertime water recycling within the Mississippi basin is on the order of $25 \%$. Gat et al. (1994) used stable isotope analyses of precipitation to estimate the contribution of evaporation from the Great Lakes to continental water vapor content. In their study they estimated a contribution of 5 to $16 \%$. These previous studies are in line with our own independent analyses and show that warm-season precipitation events have a relatively strong local signature, and that these rates are reasonably well constrained by models, at least on seasonal timescales.

\section{Conclusions}

1. The oxygen and hydrogen isotope composition of water vapor observed from a very tall tower in the upper Midwest, United States, shows a very strong seasonal amplitude $\left(\delta^{18} \mathrm{O}_{\mathrm{v}}=-40.2\right.$ to $-15.9 \%$ and $\delta^{2} \mathrm{H}_{\mathrm{v}}=-278.7$ to $-113.0 \%$ ). The seasonal amplitude is driven by synoptic scale (Rayleigh) processes that are strongly modulated by planetary boundary layer processes including evaporation and entrainment.
2. Isoforcing calculations support that evaporation can have a dominant influence on the fluctuations of $\delta^{18} \mathrm{O}_{\mathrm{v}}$. Wavelet coherence analyses were used to demonstrate that the deuterium excess of water vapor is influenced by both synoptic and planetary boundary layer processes. Based on coherence and phase relationships, it appears that changes in evaporation often lead changes in deuterium excess.

3. Based on multiple lines of evidence (modeling and tall tower isotope observations), the humidification of the planetary boundary layer and the occurrence of extreme dew point temperatures have a strong terrestrial evaporation fingerprint. At water vapor mixing ratios greater than $25 \mathrm{mmol} \mathrm{mol}^{-1}$ the locally generated vapor from evaporation accounts for 40 to $60 \%$ of the water vapor in the planetary boundary layer. Source footprint analyses for extreme dew point events indicate that the source of this evaporation is largely $(\approx 90 \%)$ traceable to agricultural crops within the region.

4. The contribution of evaporation to growing season precipitation (precipitation recycling ratio) was estimated using a simple isotope mixing model that was constrained using 3 years of tall tower isotope observations of water vapor and 6 years of isotope observations of precipitation. A Monte Carlo analysis indicates that the precipitation recycling ratio is about $30 \%$ and in relatively good agreement with estimates derived from numerical weather models.

\section{Data availability}

The tall tower water vapor isotope data reported in this paper can be made available upon request and will be hosted at http: //www.biometeorology.umn.edu/research/data-archives. The supporting NCEP NFL data used for the WRF simulations are available at http://rda.ucar.edu/datasets/ds083.2/.

\section{The Supplement related to this article is available online at doi:10.5194/acp-16-5139-2016-supplement.}

Acknowledgements. Funding for this research was provided by the Minnesota Corn Research and Promotion Council (4101-14SP). Support for the Rosemount, Minnesota, AmeriFlux core site was provided by the U.S. Department of Energy's Office of Science. Xuhui Lee acknowledges support from the US National Science Foundation (grant 1520684). We thank Minnesota Public Radio and Tom Nelson for providing logistical support for the tall tower (KCMP) isotope observations. We acknowledge the support from the University of Minnesota Supercomputing Institute (MSI) for Advanced Computational Research. Finally, we wish to thank the reviewers and editor for their thoughtful comments and criticism 
that helped improve the quality of this paper.

Edited by: H. Wernli

\section{References}

Aemisegger, F., Pfahl, S., Sodemann, H., Lehner, I., Seneviratne, S. I., and Wernli, H.: Deuterium excess as a proxy for continental moisture recycling and plant transpiration, Atmos. Chem. Phys., 14, 4029-4054, doi:10.5194/acp-14-4029-2014, 2014.

Aemisegger, F., Spiegel, J. K., Pfahl, S., Sodemann, H., Eugster, W., and Wernli, H.: Isotope meteorology of cold front passages: A case study combining observations and modeling, Geophys. Res. Lett., 42, 5652-5660, doi:10.1002/2015GL063988, 2015.

Blanken, P., Spence, C., Hedstrom, N., and Lenters, J.: Evaporation from Lake Superior: 1. Physical controls and processes, J. Great Lakes Res., 37, 707-716, 2011.

Bosilovich, M. and Schubert, S.: Water vapor tracers as diagnostics of the regional hydrologic cycle, J. Hydrometeorol., 3, 149-165, 2002.

Changnon, D., Sandstrom, M., and Schaffer, C.: Relating changes in agricultural practices to increasing dew points in extreme Chicago heat waves, Clim. Res., 24, 243-254, 2003.

Chen, F., Mitchell, K., Schaake, J., Xue, Y. K., Pan, H. L., Koren, V., Duan, Q. Y., Ek, M., and Betts, A.: Modeling of land surface evaporation by four schemes and comparison with FIFE observations, J. Geophys. Res.-Atmos., 101, 7251-7268, doi:10.1029/95JD02165, 1996.

Chung, E.-S., Soden, B., Sohn, B. J., and Shi, L.: Uppertropospheric moistening in response to anthropogenic warming, P. Natl. Acad. Sci. USA, 111, 11636-11641, doi:10.1073/pnas.1409659111, 2014.

Clark, I. and Fritz, P.: Environmental isotopes in hydrogeology, CRC Press, Boca Raton, Florida, USA, 1997.

Craig, H.: Isotopic variations in meteoric waters, Science, 133, 1702-1703, 1961.

Dai, A. G.: Recent climatology, variability, and trends in global surface humidity, J. Climate, 19, 3589-3606, 2006.

Dansgaard, W.: Stable isotopes in precipitation, Tellus, 16, 436468, 1964

Daubechies, I.: The wavelet transform time-frequency localization and signal analysis, IEEE T. Inform. Theory, 36, 961-1004, 1990.

Delattre, H., Vallet-Coulomb, C., and Sonzogni, C.: Deuterium excess in the atmospheric water vapour of a Mediterranean coastal wetland: regional vs. local signatures, Atmos. Chem. Phys., 15, 10167-10181, doi:10.5194/acp-15-10167-2015, 2015.

Eilers, P. and Goeman, J.: Enhancing scatter plots with smoothed densities, Bioinformatics, 20, 623-628, 2004.

Eltahir, E. and Bras, R.: Precipitation Recycling, Reviews in Geophysics, 34, 367-378, 1996.

Farlin, J., Lai, C., and Yoshimura, K.: Influence of synotpic weather events on the isotopic composition of atmospheric moisture in a coastal city of western United States, Water Resour. Res., 49, $1-12,2013$

Gat, J.: Oxygen and hydrogen isotopes in the hydrologic cycle, Annu. Rev. Earth Pl. Sc., 24, 225-262, 1996.
Gat, J. and Airey, P.: Stable water isotopes in the atmosphere/biosphere/lithosphere interface: Scaling-up from the local to continental scale, under humid and dry conditions, Global Planet. Change, 51, 25-33, 2006.

Gat, J., Bowser, C., and Kendall, C.: The Contribution of evaporation from the Great-Lakes to the continental atmosphere - Estimate based on stable-isotope data, Geophys. Res. Lett., 21, 557560, 1994.

Gerbig, C., Lin, J. C., Wofsy, S. C., Daube, B. C., Andrews, A. E., Stephens, B. B., Bakwin, P. S., and Grainger, C. A.: Toward constraining regional-scale fluxes of $\mathrm{CO}_{2}$ with atmospheric observations over a continent: 2 . Analysis of COBRA data using a receptor-oriented framework, J. Geophys. Res.-Atmos., 108, 4757, doi:10.1029/2003JD003770, 2003.

Griffis, T.: Tracing the flow of carbon dioxide and water vapor between the biosphere and atmosphere: A review of optical isotope techniques and their application, Agr. Forest Meteorol., 174-175, 85-109, 2013.

Griffis, T., Baker, J., Sargent, S., Erickson, M., Corcoran, J., Chen, M., and Billmark, K.: Influence of $\mathrm{C}_{4}$ vegetation on ${ }^{13} \mathrm{CO}_{2}$ discrimination and isoforcing in the Upper Midwest, United States, Global Biogeochem. Cy., 24, GB4006, doi:10.1029/2009GB003594, 2010a.

Griffis, T., Sargent, S., Lee, X., Baker, J., Greene, J., Erickson, M., Zhang, X., Billmark, K., Schultz, N., Xiao, W., and Hu, N.: Determining the oxygen isotope composition of evapotranspiration using eddy covariance, Bound.-Lay. Meteorol., 137, 307-326, doi:10.1007/s10546-010-9529-5, 2010b.

Griffis, T., Lee, X., Baker, J., Sargent, S., Schultz, N., Erickson, M., Zhang, X., Fassbinder, J., Billmark, K., Xiao, W., and Hu, N.: Oxygen isotope composition of evapotranspiration and its relation to $\mathrm{C}_{4}$ photosynthetic discrimination, J. Geophys. Res.Biogeo., 116, G01035, doi:10.1029/2010JG001514, 2011.

Griffis, T., Lee, X., Baker, J., Russelle, M., Zhang, X., Venterea, R., and Millet, D.: Reconciling the differences between top-down and bottom-up estimates of nitrous oxide emissions for the US Corn Belt, Global Biogeochem. Cy., 27, 746-754, 2013.

Grinsted, A., Moore, J., and Jevrejeva, S.: Application of the cross wavelet transform and wavelet coherence to geophysical time series, Nonlinear Proc. Geophy., 11, 561-566, 2004.

Harding, K.: Examining the drivers of current and future changes in Central US warm-season rainfall, $\mathrm{PhD}$ dissertation, University of Minnesota, Saint Paul, Minnesota, USA, 2014.

$\mathrm{He}, \mathrm{H}$. and Smith, R.: Stable isotope composition of water vapor in the atmospheric boundary layer above the forests of New England, J. Geophys. Res., 104, 11657-11673, 1999.

Hu, L., Millet, D. B., Baasandorj, M., Griffis, T. J., Travis, K. R., Tessum, C. W., Marshall, J. D., Reinhart, W. F., Mikoviny, T., Mueller, M., Wisthaler, A., Graus, M., Warneke, C., and de Gouw, J.: Emissions of C-6-C-8 aromatic compounds in the United States: Constraints from tall tower and aircraft measurements, J. Geophys. Res.-Atmos., 120, 826-842, doi:10.1002/2014JD022627, 2015a.

Hu, L., Millet, D. B., Baasandorj, M., Griffis, T. J., Turner, P., Helmig, D., Curtis, A. J., and Hueber, J.: Isoprene emissions and impacts over an ecological transition region in the US Upper Midwest inferred from tall tower measurements, J. Geophys. Res.-Atmos., 120, 3553-3571, doi:10.1002/2014JD022732, 2015 b. 
Hu, Z., Wen, X., X.Sun, Li, L., Yu, G., Lee, X., and Li, S.: Partitioning of Evapotranspiration through oxygen isotopic measurements of water pools and fluxes in a temperate grassland, J. Geophys. Res.-Biogeo., 119, 358-371, 2014.

Huang, L. and Wen, X.: Temporal variations of atmospheric water vapor $\delta \mathrm{D}$ and $\delta^{18} \mathrm{O}$ above an arid artificial oasis cropland in the Heihe River Basin, J. Geophys. Res.-Atmos., 119, 11456-11476, 2014.

Jacob, H. and Sonntag, C.: An 8-Year Record Of The SeasonalVariation Of ${ }^{2} \mathrm{H}$ And ${ }^{18} \mathrm{O}$ In Atmospheric Water-Vapor And Precipitation At Heidelberg, Germany, Tellus B, 43, 291-300, 1991.

Johnson, L., Sharp, Z., Galewsky, J., Strong, M., Pelt, A. V., Dong, F., and Noone, D.: Hydrogen isotope correction for laser instrument measurement bias at low water vapor concentration using conventional isotope analyses: Application to measurements from Mauna Loa Observatory, Hawaii, Rapid Commun. Mass Sp., 25, 608-616, 2011.

Jouzel, J.: Water stable isotopes: Atmospheric composition and applications in polar ice core studies, in: The Atmosphere: Treatise on Geochemistry, vol. 4, Treatise on Geochemistry, 213-243, Elsevier-Pergamon, Oxford, New York, USA, 2003.

Keeling, C. D.: The concentration and isotopic abundances of atmospheric carbon dioxide in rural areas, Geochim. Cosmochim. Ac., 13, 322-334, 1958.

Kong, Y., Pang, Z., and Froehlich, K.: Quantifying recycled moisture fraction in precipitation of an arid region using deuterium excess, Tellus B, 65, 19251, doi:10.3402/tellusb.v65i0.19251, 2013.

Lai, C.-T. and Ehleringer, J.: Deuterium excess reveals diurnal sources of water vapor in forest air, Oecologia, 165, 213-223, 2011.

Lee, H., Smith, R., and Williams, J.: Water vapour ${ }^{18} \mathrm{O} /{ }^{16} \mathrm{O}$ isotope ratio in surface air in New England, USA, Tellus B, 58, 293-304, 2006.

Lee, X., Sargent, S., Smith, R., and Tanner, B.: In-situ measurement of the water vapor ${ }^{18} \mathrm{O} /{ }^{16} \mathrm{O}$ isotope ratio for atmospheric and ecological applications, J. Atmos. Ocean. Tech., 22, 555-565, 2005.

Lee, X., Griffis, T., Baker, J., Billmark, K., Kim, K., and Welp, L.: Canopy-scale kinetic fractionation of atmospheric carbon dioxide and water vapor isotopes, Global Biogeochem. Cy., 23, GB1002, doi:10.1029/2008GB003331, 2009.

Lee, X., Huang, J., and Patton, E.: A large-eddy simulation study of water vapour and carbon dioxide isotopes in the atmospheric boundary layer, Bound.-Lay. Meteorol., 145, 229-248, 2012.

Lee, X. H., Kim, K., and Smith, R.: Temporal variations of the ${ }^{18} \mathrm{O} /{ }^{16} \mathrm{O}$ signal of the whole-canopy transpiration in a temperate forest, Global Biogeochem. Cy., 21, GB3013, doi:10.1029/2006GB002871, 2007.

Lin, J., Gerbig, C., Wofsy, S., Andrews, A., Daube, B., Davis, K., and Grainger, C.: A near-field tool for simulating the upstream influence of atmospheric observations: The Stochastic Time-Inverted Lagrangian Transport (STILT) model, J. Geophys. Res.-Atmos., 108, 4493, doi:10.1029/2002JD003161, 2003.

Majoube, M.: Fractionnement en oxygene-18 et en deuterium entre l'eau et sa vapeur, J. Chim. Phys., 68, 1423-1436, 1971.

McNaughton, K. and Spriggs, T.: A mixed-layer model for regional evaporation, Bound.-Lay. Meteorol., 34, 243-262, 1986.
Min, S., Zhang, X., Zwiers, F., and Hegerl, G.: Human contribution to more-intense precipitation extremes, Nature, 470, 378-381, 2011.

National Centers for Environmental Prediction/National Weather Service/NOAA/U.S. Department of Commerce: NCEP FNL Operational Model Global Tropospheric Analyses, continuing from July 1999, Research Data Archive at the National Center for Atmospheric Research, Computational and Information Systems Laboratory, doi:10.5065/D6M043C6 (last access: 28 May 2015), 2000.

Nguyen, T. K. V., Capps, S. L., and Carlton, A. G.: Decreasing Aerosol Water Is Consistent with OC Trends in the Southeast US, Environ. Sci. Tech., 49, 7843-7850, 2015.

Noone, D., Risi, C., Bailey, A., Berkelhammer, M., Brown, D. P., Buenning, N., Gregory, S., Nusbaumer, J., Schneider, D., Sykes, J., Vanderwende, B., Wong, J., Meillier, Y., and Wolfe, D.: Determining water sources in the boundary layer from tall tower profiles of water vapor and surface water isotope ratios after a snowstorm in Colorado, Atmos. Chem. Phys., 13, 1607-1623, doi:10.5194/acp-13-1607-2013, 2013.

Papale, D., Reichstein, M., Aubinet, M., Canfora, E., Bernhofer, C., Kutsch, W., Longdoz, B., Rambal, S., Valentini, R., Vesala, T., and Yakir, D.: Towards a standardized processing of Net Ecosystem Exchange measured with eddy covariance technique: algorithms and uncertainty estimation, Biogeosciences, 3, 571-583, doi:10.5194/bg-3-571-2006, 2006.

Sachs, L.: Angewandte Statistik: Anwendung Statistischer Methoden, Springer, Berlin, Germany, 1996.

Santer, B. D., Mears, C., Wentz, F. J., Taylor, K. E., Gleckler, P. J., Wigley, T. M. L., Barnett, T. P., Boyle, J. S., Brueggemann, W., Gillett, N. P., Klein, S. A., Meehl, G. A., Nozawa, T., Pierce, D. W., Stott, P. A., Washington, W. M., and Wehner, M. F.: Identification of human-induced changes in atmospheric moisture content, P. Natl. Acad. Sci. USA, 104, 15248-15253, doi:10.1073/pnas.0702872104, 2007.

Schmidt, G., Ruedy, R., Miller, R., and Lacis, A.: Attribution of the present-day total greenhouse effect, J. Geophys. Res.-Atmos., 115, D20106, doi:10.1029/2010JD014287, 2010.

Schultz, N.: Tracing the source and transport of atmospheric water vapor using stable isotope techniques, MS Thesis, University of Minnesota, Saint Paul, Minnesota, USA, 1-95, 2011.

Schultz, N., Griffis, T., Lee, X., and Baker, J.: Identification and correction of spectral contamination in ${ }^{2} \mathrm{H} /{ }^{1} \mathrm{H}$ and ${ }^{18} \mathrm{O} /{ }^{16} \mathrm{O}$ measured in leaf, stem, and soil water, Rapid Commun. Mass Sp., 25, 3360-3368, 2011.

Simonin, K., Link, P., Rempe, D., Miller, S., Oshun, J., Bode, C., Dietrich, W., Fung, I., and Dawson, T.: Vegetation induced changes in the stable isotope composition of near surface humidity, Ecohydrology, 7, 936-949, 2014.

Soderberg, K., Good, S. P., O’Connor, M., Wang, L., Ryan, K., and Caylor, K. K.: Using atmospheric trajectories to model the isotopic composition of rainfall in central Kenya, Ecosphere, 4, UNSP33, doi:10.1890/ES12-00160.1, 2013.

Stewart, M.: Stable isotope fractionation due to evaporation and isotopic exchange of falling waterdrops: Applications to Atmospheric Processes and Evaporation of Lakes, J. Geophys. Res., 80, 1133-1146, 1975.

Tian, L., Yao, T., MacClune, K., White, J., Schilla, A., Vaughn, B., Vachon, R., and Ichiyanagi, K.: Stable isotopic variations in west 
China: A consideration of moisture sources, J. Geophys. Res., 112, D10112, doi:10.1029/2006JD007718, 2007.

Torrence, C. and Compo, G.: A practical Guide to wavelet analysis, Bull. Am. Meteorol. Soc., 79, 61-78, 1998.

Trenberth, K.: Atmospheric moisture and residence times and cycling: Implications for rainfall rates and climate change, Climatic Change, 39, 667-694, 1998.

Trenberth, K.: Changes in precipitation with climate change, Clim. Res., 47, 123-138, 2011.

Trenberth, K. and Asrar, G.: Challenges and opportunities iin water cycle research: WCRP contributions, Surv. Geophys., 35, 515$532,2014$.

Trenberth, K., Jones, P., Ambenje, P., Bojariu, R., Easterling, D., Tank, A. K., Parker, D., Rahimzadeh, F., Renwick, J., Rusticucci, M., Sonden, B., and Zhai, P.: Observations: Surface and Atmospheric Climate Change, chap. 3, in: Climate Change 2007: The Physical Science Basis. Contribution of Working Group 1 to the Fourth Assessment Report of the Intergovernmental Panel on Climate Change, Cambridge University Press, Cambridge, UK and New York, NY, USA, 235-336, 2007a.

Trenberth, K., Smith, L., Qian, T., Dai, A., and Fasullo, J.: Estimates of the global water budget and its annual cycle using observational and model data, J. Hydrometeorol., 8, 758-769, $2007 \mathrm{~b}$.

Vallet-Coulomb, C., Gasse, F., and Sonzogni, C.: Seasonal evolution of the isotopic composition of atmospheric water vapour above a tropical lake: Deuterium excess and implication for water recycling, Geochim. Cosmochim. Ac., 72, 4661-4674, doi:10.1016/j.gca.2008.06.025, 2008.

Wang, L., Caylor, K., Villegas, J., Barron-Gafford, G., Breshears, D., and Huxman, T.: Partitioning evapotranspiration across gradients of woody plant cover: Assessment of a stable isotope technique, Geophys. Res. Lett., 37, L09401, doi:10.1029/2010GL043228, 2010.

Welp, L., Lee, X., Griffis, T., Wen, X., Xiao, W., Li, S., Sun, X., Hu, Z., Martin, M. V., and Huang, J.: A meta-analysis of water vapor deuterium-excess in the midlatitude atmospheric surface layer, Global Biogeochem. Cy., 26, GB3021, doi:10.1029/2011GB004246, 2012.
Welp, L. R., Lee, X., Kim, K., Griffis, T. J., Billmark, K. A., and Baker, J. M.: $\delta^{18} \mathrm{O}$ of water vapour, evapotranspiration and the sites of leaf water evaporation in a soybean canopy, Plant Cell Environ., 31, 1214-1228, doi:10.1111/j.13653040.2008.01826.x, 2008.

Wen, X.-F., Sun, X.-M., Zhang, S.-C., Yu, G.-R., Sargent, S. D., and Lee, X.: Continuous measurement of water vapor $\mathrm{D} / \mathrm{H}$ and ${ }^{18} \mathrm{O} /{ }^{16} \mathrm{O}$ isotope ratios in the atmosphere, J. Hydrol., 349, 489500, doi:10.1016/j.jhydrol.2007.11.021, 2008.

Wen, X.-F., Zhang, S.-C., Sun, X.-M., Yu, G.-R., and Lee, X.: Water vapor and precipitation isotope ratios in Beijing, China, J. Geophys. Res.-Atmos., 115, D01103, doi:10.1029/2009JD012408, 2010.

Worden, J., Noone, D., and Bowman, K.: Importance of rain evaporation and continental convection in the tropical water cycle, Nature, 445, 528-532, 2007

Yu, W., Yao, T., Tian, L., , Li, Z., Sun, W., and Wang, Y.: Relationships between $\delta^{18} \mathrm{O}$ in summer precipitation and temperature and moisture trajectories at Muztagata, western China, Science China, 49, 27-35, 2006.

Zangvil, A., Portis, D., and Lamb, P.: Investigation of the large-scale atmospheric moisture field over the Midwestern United States in relation to summer precipitation. Part II: Recycling of local evapotranspiration and association with soil moisture and crop yields, J. Climate, 17, 3283-3301, 2004

Zhang, X., Lee, X., Griffis, T. J., Baker, J. M., and Xiao, W.: Estimating regional greenhouse gas fluxes: an uncertainty analysis of planetary boundary layer techniques and bottom-up inventories, Atmos. Chem. Phys., 14, 10705-10719, doi:10.5194/acp14-10705-2014, 2014.

Zhao, L., Wang, L., Liu, X., Xiao, H., Ruan, Y., and Zhou, M.: The patterns and implications of diurnal variations in the dexcess of plant water, shallow soil water and air moisture, Hydrol. Earth Syst. Sci., 18, 4129-4151, doi:10.5194/hess-18-41292014, 2014. 